\title{
UX Designer and Software Developer at the Mirror: Assessing Sensory Immersion and Emotional Involvement in Virtual Museums
}

\author{
EVA PIETRONI, ALFONSINA PAGANO and BRUNO FANINI \\ Institute for Technology applied to Cultural Heritage, National Research Council, \\ Rome, Italy
}

\begin{abstract}
Virtual Museums (VMs) and their audiences have always been studied as separated worlds. Recently the importance of cross-methodological studies has been accepted by the academic sector for their usefulness in the process of assessing the impact of such VMs. Hedonic aspects, such as emotions, senses, perception, and environmental atmosphere rather than technicalities, like usability and affordance, have indeed played a precise and crucial role in the meaning-making of the world around us. This contribution will highlight the need for a collaborative sharing of ideas among designers and developers, creators and technicians, in order to reach sensory immersion and emotional involvement in VMs that will translate into enhanced participation and the predisposition to assimilate and memorize cultural contents. It has been stated that "a virtual museum is a digital entity." As such, it is inevitably based on technology, on its user interface (UI), on the visualization solutions it employs, and on its usability and ability to interact with the end user in order to transfer a certain message. VMs are designed to complement, enhance, or augment the ordinary museum experience through contextualization, narration, personalization, interactivity and richness of content. This contribution originates not only from the lessons learned in twenty years of research by CNR ITABC, but it also moves one step further in the direction of exchanged experiences and good practices between the humanistic and the technological sectors, therefore contributing to the promotion of lifelong learning in Virtual Museums.
\end{abstract}

Key words:

Virtual museums, user experience, embodiment, sensory immersion, emotions, narrative approach.

SDH Reference:

Eva Pietroni et al. 2018. UX Designer and Software Developer at the Mirror: Assessing Sensory

Immersion and Emotional Involvement in Virtual Museums. SDH, 2, 1, 13-41

DOI : $10.14434 /$ sdh.v2i1.24634

\section{INTRODUCTION: PERCEPTION, EMOTION, COGNITION IN VMS}

Nowadays, Virtual Museums (VMs) are undergoing a complex process that is the result of many elements: the digital shift and changes in people's attendance at real museums; the new contexts of

Author's address: Eva Pietroni, Alfonsina Pagano and Bruno Fanini, Institute for Technologies applied to Cultural Heritage (ITABC), National Research Council (CNR), Area della Ricerca Roma 1, Via Salaria Km. 29,300, 00010 - Montelibretti (Rome), Italy; email: eva.pietroni@itabc.cnr.it@cnr.it

(c) [2018] by the authors; licensee Studies in Digital Heritage, IU, Bloomington (IN), USA. This article is an open access article distributed under the terms and conditions of the Creative Commons Attribution License (CC BY-NC) 


\section{2:14 E. Pietroni, et al.}

usage of mobile apps and physical installations; different kinds of participation and engagement towards cultural products; and an increase of shareable experiences among users. Not surprisingly, in a period of transition like this, it becomes difficult to assess the impact(s) of VMs and the side effects coming from the unpredictability of their use by several target groups. Virtual museums are usually complex to design, because they need to be addressed to a wide audience, very heterogeneous in terms of culture, provenience, age and gender, and technological literacy. In this, VMs differ, for example, from video-games or even from TV productions, where the users' profiling is generally much more defined.

Designers of user experience and software developers must work together in order to plan and implement cost-effective and user-friendly interfaces, extremely versatile, dynamic and updated to reflect the latest trends. In this respect, indeed, not only do informatics and computer graphics need to be considered, but also psychology, cognition, information architecture, and art.

When designing a VM we need to have clearly in mind how a user gets in contact with it; which are the receptive canals that he activates in his mind; how the interaction takes place; and what are the benefits derived from such interaction in terms of satisfaction, sensory and emotional involvement, and learning in the proposed virtual world.

The cognitive process relevant for VMs is perception, referring to a process of sensory stimulation and significance that our mind activates once in front of something. It has always been studied as a source of knowledge and as a mental phenomenon in its own right. Visual perception and proprioception represent the first cognitive ability, given that it is with our eyes and body that we know the world around us-including the virtual one. In the field of VMs, this is still a prime way to explore and live the three-dimensional spaces. Sensations and perceptions are thus involved in the experience and in the learning processes, as is presented in David Kolb's Experiential Learning Model (ELM) and in Bloom's Taxonomy of cognition and social context.

Because perception is a transaction between the world and "us", intended as perceivers, the most interesting issue is investigating the kind of relation between the two spheres [Gold 2001]. Cognition and emotions are here essential: the former is the mental process of knowledge acquisition and understanding by means of senses, thoughts, and live experiences [Sternberg and Sternberg 2009]; it generates attention, memorization and comprehension, generally cognitive processes that use existing knowledge to generate new knowledge (Fig.1). That is also what usually happens when we interact with a VM: the use of a device to access cultural information recalls the memory of something already familiar to the user, quotidian gestures and movements. The more the engineer and the UI designer are good at designing and developing the intermediate interface of play, the more the user will not have difficulties in using such devices. Social transmission and the cultural growth, therefore, take into account the reusability of our past experiences, the lessons learned, and the emotions felt. Emotions work as indicators of the "quality" of such experiences and, together with reasoning, push us in one direction or another, letting us to make this or that choice.

Culture-intended as values, symbols, ideas and beliefs-moves from one person to another mainly in the form of behaviors, spoken words, physical gestures, written texts and attitudes, as well as representations, performances, and sounds. The social context in which each of us is embedded provides the needed symbols useful for our representations of the world and our linguistic 
expressions. Choices are consequently influenced by the social and ambient environment (real or virtual); they allow actions to happen and, further, they lead to a shaping of experience.

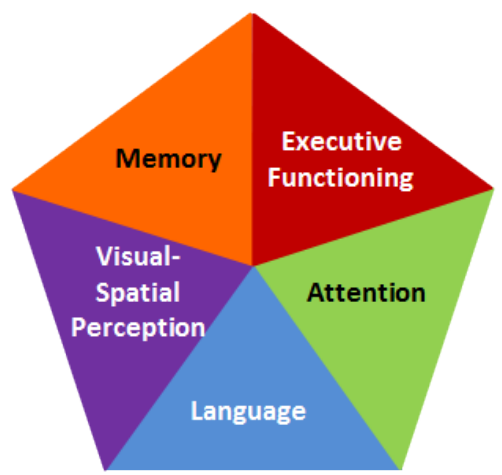

Figure 1. Cognitive domain.

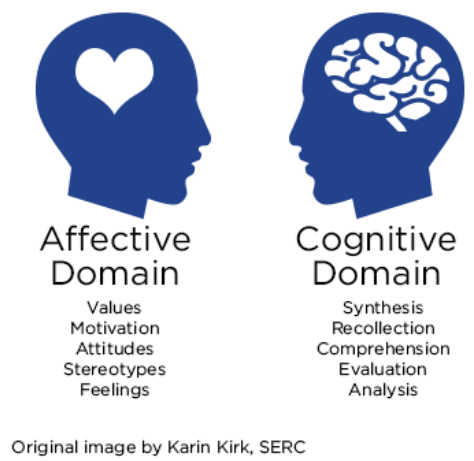

Figure 2. Affective domain vs. cognitive domain.

Emotions are discrete and consistent responses to internal or external events that have a particular significance for a person. From a general point of view, we can affirm that they are mental states with a certain degree of pleasure or displeasure [Cabanac 2002] that influence our behavior and the way of acting in a social context [Schacter 2011]. Emotions are strictly connected with the mind and the individual's mental faculties. Sure enough, the affective domain, composed of values, motivations, personal attitudes and feelings are influenced by, and influence, at the same time, the cognitive domain (Fig. 2), i. e., memory, language, level of attention, and so on.

If we were to describe a moment of experience, we should include a third factor: the psychomotor domain, the ability of an individual to act in a social and natural context (Fig. 4). It is true that a meaning-making episode can occur when a person is passive, for example, when he listens to somebody else explaining how to assemble a product. Nevertheless, it can be much more effective and powerful if the same person is active, that is, if he manually tries to assemble that specific product with the help of somebody. This situation is called learn-by-doing (also known as experiential learning) and it is central to the process of knowledge acquisition and memorization.

How actions and knowledge are connected has been studied [Dewey 1938]. Specifically, Kolb's model [Loo 2002] is the paradigm we refer to in order to explain the learn-by-doing experience for the VM sector (Fig. 3). First of all, a person interacts with a VM concretely by pushing, touching, listening to or simply watching it. Secondly, the pedagogical presence in the VM's content (such as visibility, accessibility, memorability, etc.) arises during the interaction and while the person observes what is happening around him. Then, the person activates a process of information absorption and abstraction in his mind in order to understand what he has just observed and played, trying to give meaning to things and actions. Once he understands his role, he gets involved in the interaction and continues experimenting with the VM. In so doing, the person finally has a real experience of the VM and acquires new units of information. 


\section{2:16 E. Pietroni, et al.}

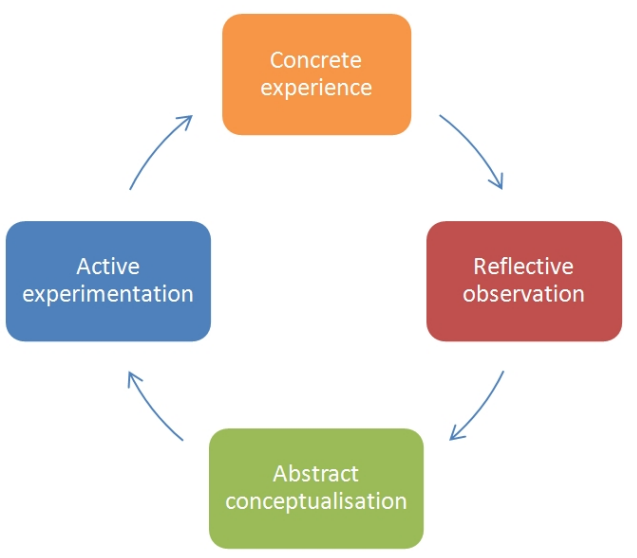

Figure 3. The Experiential Learning Model (ELM) of Kolb.

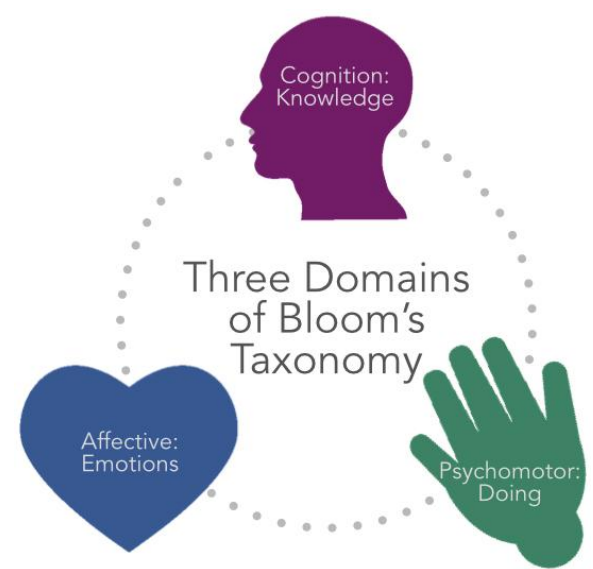

Figure 4. Bloom's Taxonomy of cognition and social context.

According to David A. Kolb (who helped develop the modern theory of experiential learning in the 70 s, based on the work of Jean Piaget ${ }^{1}$ ), knowledge is continuously collected and processed by our minds through personal and environmental experiences [Merriam et al. 2007] [Ingold 2000]. This is also confirmed by Bloom's taxonomy, which presents the three spheres that should influence our behavior and learning moments: cognition, affection and psychomotor skills (Fig. 4).

Learning is thus a complex process that involves several components of human perception, mind, and behavior [Bateson 1972, 1979]. It does not arise only from our reasoning, but it also requires curiosity, engagement, interest, and attention: in one word, "motivation." Willingness is a key factor in the process of experiencing and meaning-making; without it we cannot learn and memorize anything. Motivation originates when the cultural content to be transmitted is able to get in touch with our personal sphere of life [Varela et al. 1991] [Maturana and Varela 1980]. Emotions are fundamental to stimulating a feeling of participation, self-identification, appropriation and elaboration of meaning. They immediately jump-start our senses and cognitive faculties, transforming the purely informative level into a vibrant experience [Arnheim 1954]. In such a way, the approach to the cultural content turns out not only to be deep and personal, intimate and exclusive, but also something that we would like to share with others. In this act of sharing, the significance can be even multiplied and strengthened [Gallese 2005].

The aim of this publication is therefore to provide a general overview on how to assess sensory immersion and emotional involvement in VMs for cultural transmission, from both designers' and developers' points of view. The idea is to come up with practical suggestions and guidelines useful for researchers in this field. Particular attention will be paid to describing:

\footnotetext{
1 Jean Piaget (1896, Neuchâtel - 1980, Geneva) was one of the most important and influential scientists in the field of Developmental Psychology. He believed that individuals have the capacity to do "abstract symbolic reasoning." His work can be compared to Lev Vygotsky, Sigmund Freud, and Erik Erikson, who were also great contributors in the same field.
} 
- a grid of indicators to be taken into account when dealing with perception (senses), emotions and behaviors (sections 1 and 5);

- a selection of previous research and projects realized in different contexts, serving different audiences, and including different content (section 2);

- technical expedients to overcome specific issues regarding the sense of embodiment and inclusion into virtual worlds (section 3);

- various methodologies used in the cultural field to measure and assess the emotional impact on the users (sections 4 and 6).

\section{CULTURAL HERITAGE AND ITS SENSORY CONSISTENCY}

Every cultural artifact consists of a combination of materials, colors and shapes (aesthetic consistency) and in a convergence of expressive values and meanings (historical values) [Brandi 1963] [Panofsky 1996]. An artwork is an artifact created by man, using any material, endowed with aesthetic characteristics, and imitating the natural or the spiritual reality.

Art is a human creation in competition with God; it is the ability to generate life inside with images, sounds, words [Sgarbi 2002]. Art generates beauty and is able to arouse emotions, sensations and feelings, pervading our souls, bringing a feeling of harmony and happiness, shared by many people. However, there are many artistic languages and paradigms, and there is not a single unequivocal code of interpretation. Each artwork reflects the artist's opinions in the social, moral, cultural, ethical or religious context of his historical period.

The museum, real or virtual, should be able to exhibit the artwork favoring the perception of its aesthetic value, but also, it should be able to support the visitors in their attempt to understand the cultural context in which the work of art originated. Therefore, one of the museum's main functions is education, making understandable the general message that the artist wanted to transmit and, at the same time, triggering in the public a process of critical interpretation and elaboration of the meaning.

In order to be identified as a "cultural object"-which means being a transmitter of a cultural valueit is necessary that an observer is able to recognize this double essence, aesthetic and historical. This is not always obvious, because many artworks or cultural objects, coming from a context completely different from ours, have lost their ability to be "decoded," recognized and understood. Thus, inside museums or archaeological sites, we often look at objects with indifference, especially if they have lost their original beauty or they only mutely testify to ancient material culture. We consider them part of a lost world that has nothing to do with our own lives. Their sensory dimensions, their narrative value, is often neutralized behind a barrier of inaccessibility, also arising to the fact that they are exhibited following criteria of specialist taxonomy [Antinucci 2007]. The reconstruction of senses and symbolic dimensions that are "beyond" the object's appearance can, in contrast, take the visitor into the middle of a lively and powerful experience. How can this be done?

Carlo Ludovico Ragghianti (Lucca, 1910-Firenze 1987) was one of the twentieth century's leading Italian historians, critics and theoreticians of art. In some ways, he can be considered a precursor of 
VMs. Between 1948 and 1964 he created the most of his "critofilms." He invented this word to mean a special typology of films, including visual and audio contents, in which the perception and interpretation of the artworks were proposed to the public following the expressive, aesthetic, and technical paradigms of cinema. He also attributed to art a function of social education, identifying its deep essence as a means to better appreciate human knowledge and evolution. According to him, the communication of art and culture has a key role in the construction of society. As a theoretician of art and also as a theoretician of cinema, he combined his experience to create a communication paradigm able to evoke and "move" the spectator's emotions [AA. VV. 2000] [Cuccu 2003] (Fig. 5). His three volumes Arti della visione [Ragghianti 1975] present a synthesis of his research on cinema, theater, and the philosophy of art.

In his book, Arte, fare, vedere [1974], Carlo Ragghianti suggested what kind of experience he would have designed for the visitors to Michelangelo's Prigioni at the Academy Gallery in Florence. These are gigantic figures that were never completed. He had the idea of creating an expressive unity between the deep essence of the artwork, as intended by the artist, and the environmental condition of the exhibit. He imagined locating the sculptures in an underground cave, instead of in an illuminated corridor (as they are), providing the visitors with helmets and torches to discover, step by step, the space. In these conditions, the dramatic and vibrant figures would have finally appeared in the darkness, revealing their volumes in the spotlights, in all their dramatic vigor, while fighting to come out from the amorphous mass of the marble block.

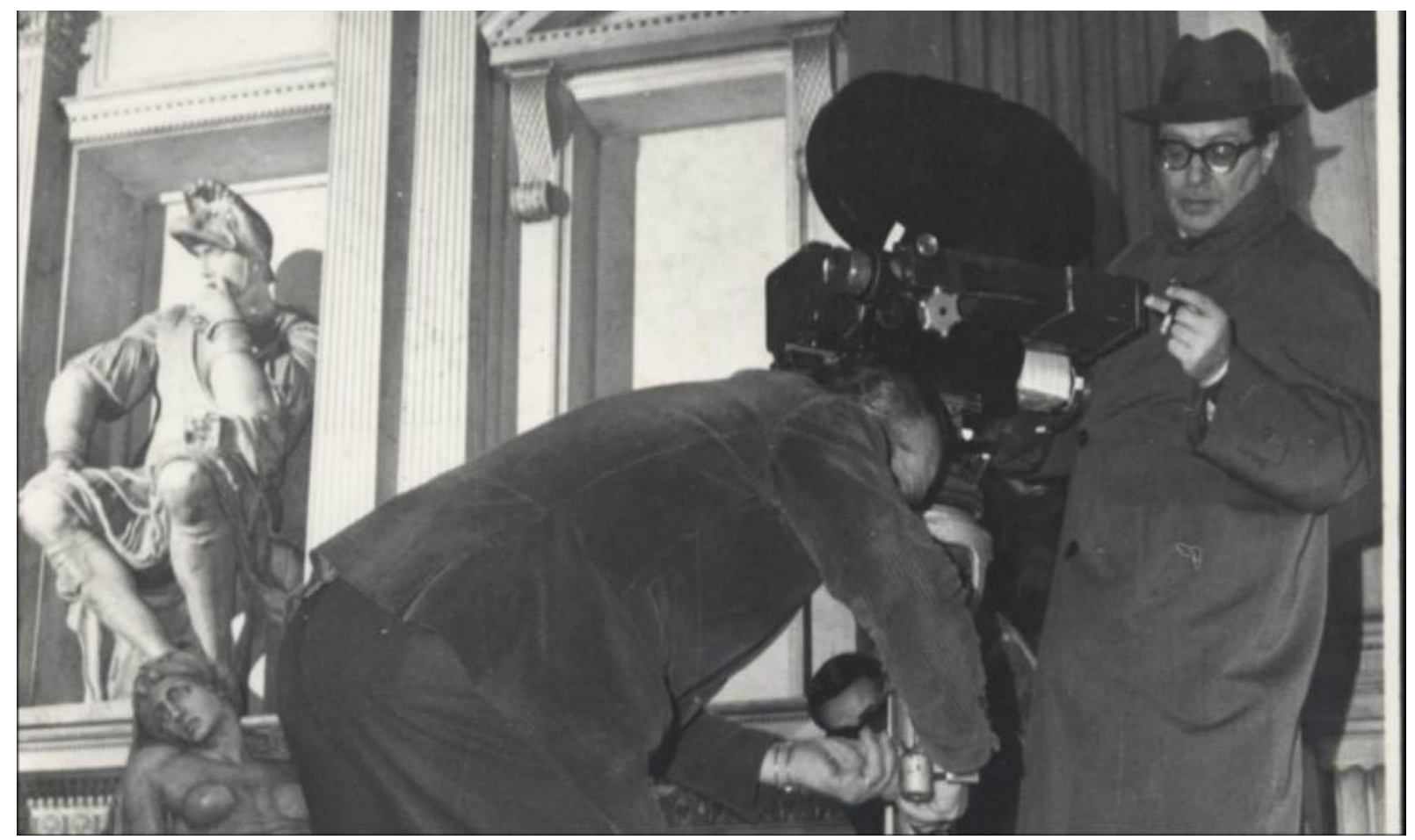

Figure 5. C. L. Ragghianti, shooting of the critofilm "Il David di Michelangelo," 1964. 
It is clear how, according to Ragghianti, the scenography, the lighting, and the itinerary are a fundamental part of the experience to better understand the meaning of an artwork and transmit the essence of the author's intention. Before the age of VMs, Carlo Ragghianti believed that the purely descriptive approach was not sufficient to create a motivation, a link between the public and the artwork and, thus, a process of engendering knowledge. That is why he applied most of his research to the creation of proper languages and paradigms of communication that would be able to engage the audience at sensory, emotional and cognitive levels.

He was a pioneer of what today is quite well accepted, at least at a theoretical level, in the domain of VMs, when we speak about audio-visual digital media, digital storytelling and interaction design. However, some of his recommendations and suggestions are still too futuristic to be accepted and adopted inside real museums today and sometimes, unfortunately, even in virtual museums.

Undoubtedly, multimedia technologies are the best means to convey contents related to cultural heritage, in particular, figurative art or music and sounds, because they engage our minds in the same sensory-motor process we automatically activate when looking at an artifact that is perceived in the first instance as image. It is a similar process of perception, elaboration and learning. The sensorymotor faculties are the most natural and immediate to be applied by human beings, because they have evolved over millions of years. In contrast, the interpretative and symbolic faculties are more recent: they have evolved over the past 100,000 years since the appearance of homo sapiens. In fact, inside a museum it is much easier and more comfortable for the visitor to look at an audio-visual animation explaining what an object could have looked like originally and which were its contexts, rather than to read and decode a lengthy written panel (that would require the effort to switch our minds from the sensory-motor to the interpretative-symbolic mode) [Antinucci 2014]. Therefore, the introduction and diffusion of digital technologies has been immediately welcomed in the domain of cultural heritage's transmission and education. Virtual environments allow the users to learn from experience, joining sensory-motor and interpretative faculties, perceiving, acting and adapting to changing circumstances, even in contexts that are no longer (or not yet) materially accessible today. They can help by representing and transmitting the original aspect of a cultural item, its context and its symbolic value, in multi-spatial and multi-temporal dimensions. Virtual contexts can be variously assembled, dismantled and mounted again in order to understand their deeper relations; they can be desynchronized, becoming scenarios of different simulations.
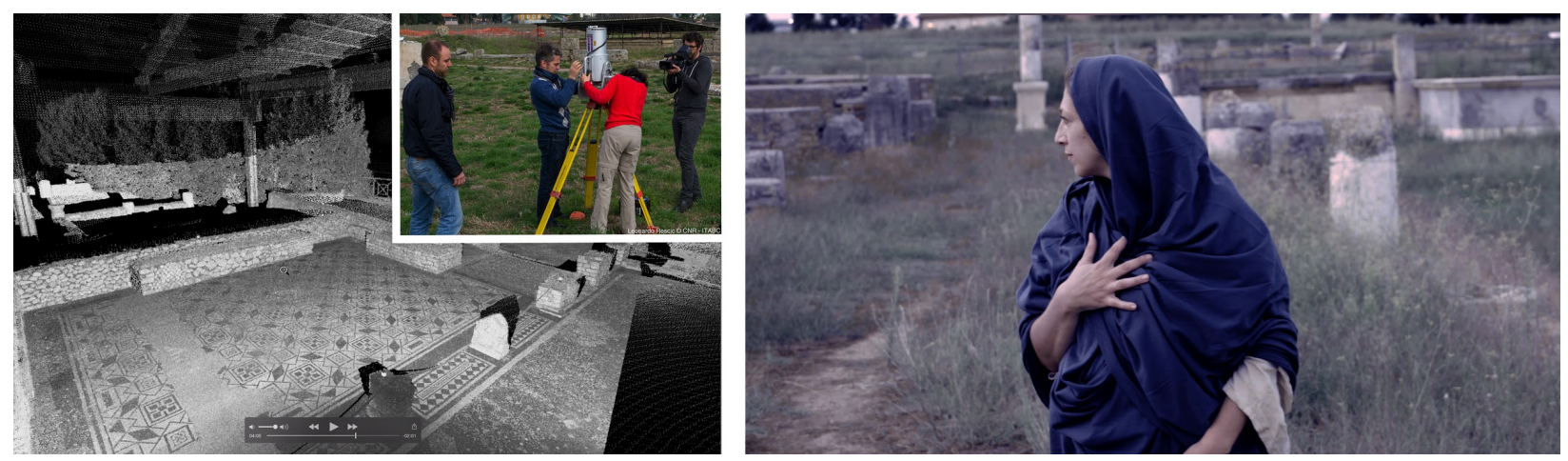

Figure 6. Documented and narrated landscapes, Lucus Feroniae, Tiber Valley (2015, CNR ITABC. 
In the last two decades, digital tools and technologies for digitization, documentation, analytic description and visualization of a cultural content have seen great advances. A huge quantity of data has been produced at multi-scale levels. However, research is still much more focused on pragmatic issues, like theoretical definition of the discipline, digitization and recording, technological implementation, digital archives, graphic optimization and GPU capabilities, rather than on philosophical and cognitive aspects, such as perception, engagement, transmission of cultural meanings, and learning (Fig. 6). This is probably owing to the fact that, until recently, the teams working on virtual museums have come mostly from computer science and digital humanities domains, with scant participation of experts from cognitive science, design, scenography, and the arts, with insufficient disciplinary cross-fertilization.

\section{THE LONG JOURNEY IN HUMAN COMPUTER INTERACTION}

Since the end of the 90s, the technological development of desktop systems has made it possible to manage graphic environments in real time on low-cost computers, affordable for everyone [Biocca 1997]. The implementation of virtual reality environments has thus represented a challenge for research, in terms of (a) visualization (real-time 3D graphics of increasingly sophisticated quality); (b) free exploration and access to informative contents associated with the 3D models; and (c) interactive interfaces.

Since 2000-1, CNR ITABC has been engaged in researching the domain of digital documentation, VR systems and virtual museums with respect to different typologies of cultural contexts, from landscape (natural, urban, archaeological) to historical sites and museum objects. Since the early years, virtual reality has been embraced, in the field of cultural heritage, for its ability to engage the visitor in an enhanced learning experience, allowing users to follow their own preferences and curiosity while building their own path of knowledge.

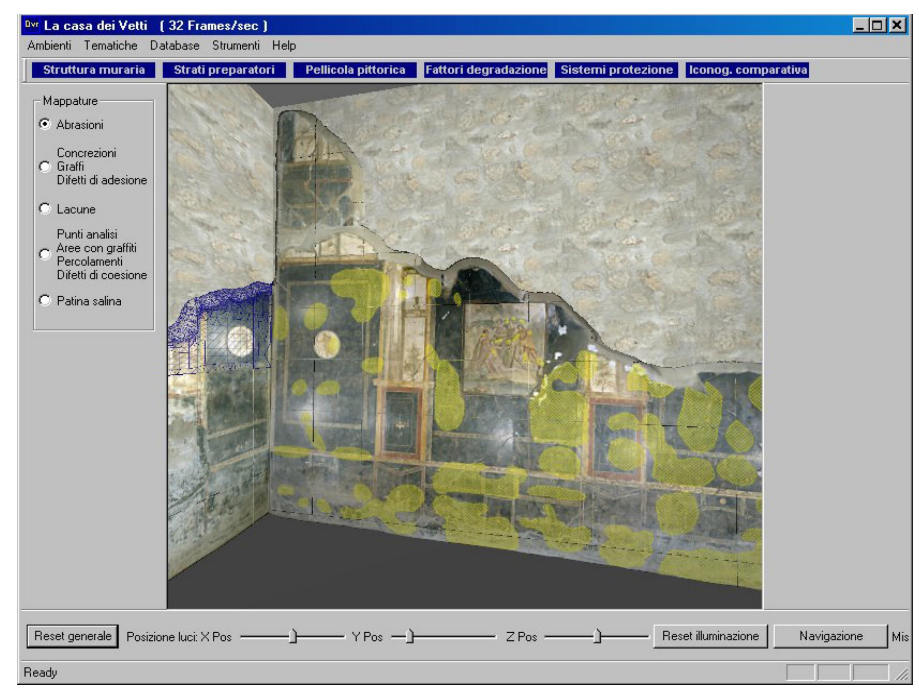

Figure 7. DVR Pompei (2001). Pioneer VR environment in OpenGL, concerning the House of Vettius in Pompeii. 3D interface with archaeometric vectorial layers mapped in 3D, Room T. CNR ITABC, Treerre, Aracnet. 
Technological improvements have been many and fast; the methodological approach has evolved, following coherently the original concept of VR as a digital ecosystem, a reliable 3D space, inclusive, interactive, multidimensional, and dense in contextualized information [Cameron and Kenderdine 2007] (Fig. 7).

We have evolved from the experience of a single user, embedded in the virtual space through his avatar, to multi-user virtual reality domains (MuD) in which a community of people, inside a real museum, was able to interact simultaneously within the three-dimensional environment, meeting and sharing objectives and strategies, and learning through imitation [Gerosa 2007] [Mellet d'Huart 2006] (Fig. 8).

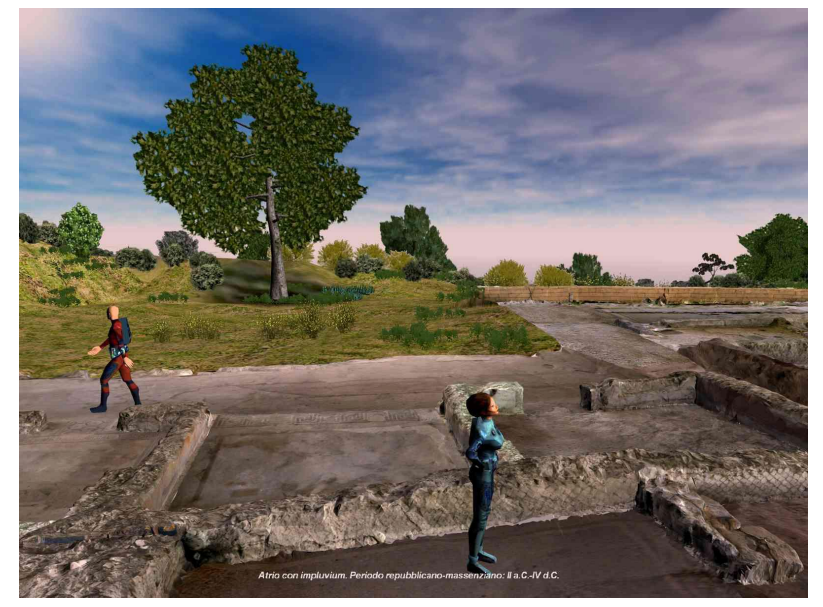

Figure 8. Virtual Museum of the ancient via Flaminia (2008), VR and multi-user domain, CNR ITABC.

In 2011, thanks to a series of sensors released by the gaming market, we began experimenting with motion-tracking systems that made it possible to interact within virtual reality environments using only body gestures: simple gestures, familiar to everyone, replacing the traditional mouse or joystick, which are difficult for a large number of visitors of real museums to use [Pietroni and Adami 2014] [Pescarin et al. 2013] (Figs. 9 and 10).

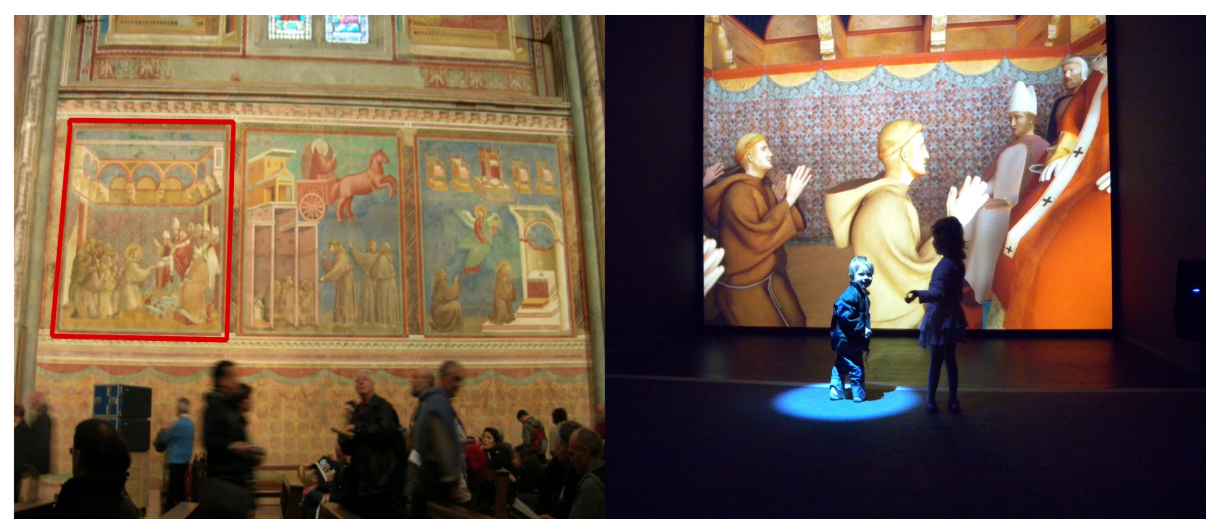

Figure 9. The Approval of the Franciscan Rule: Virtual Experience among the characters of Giotto's work (2010), by CNR in collaboration with BCAA and Softlogic 


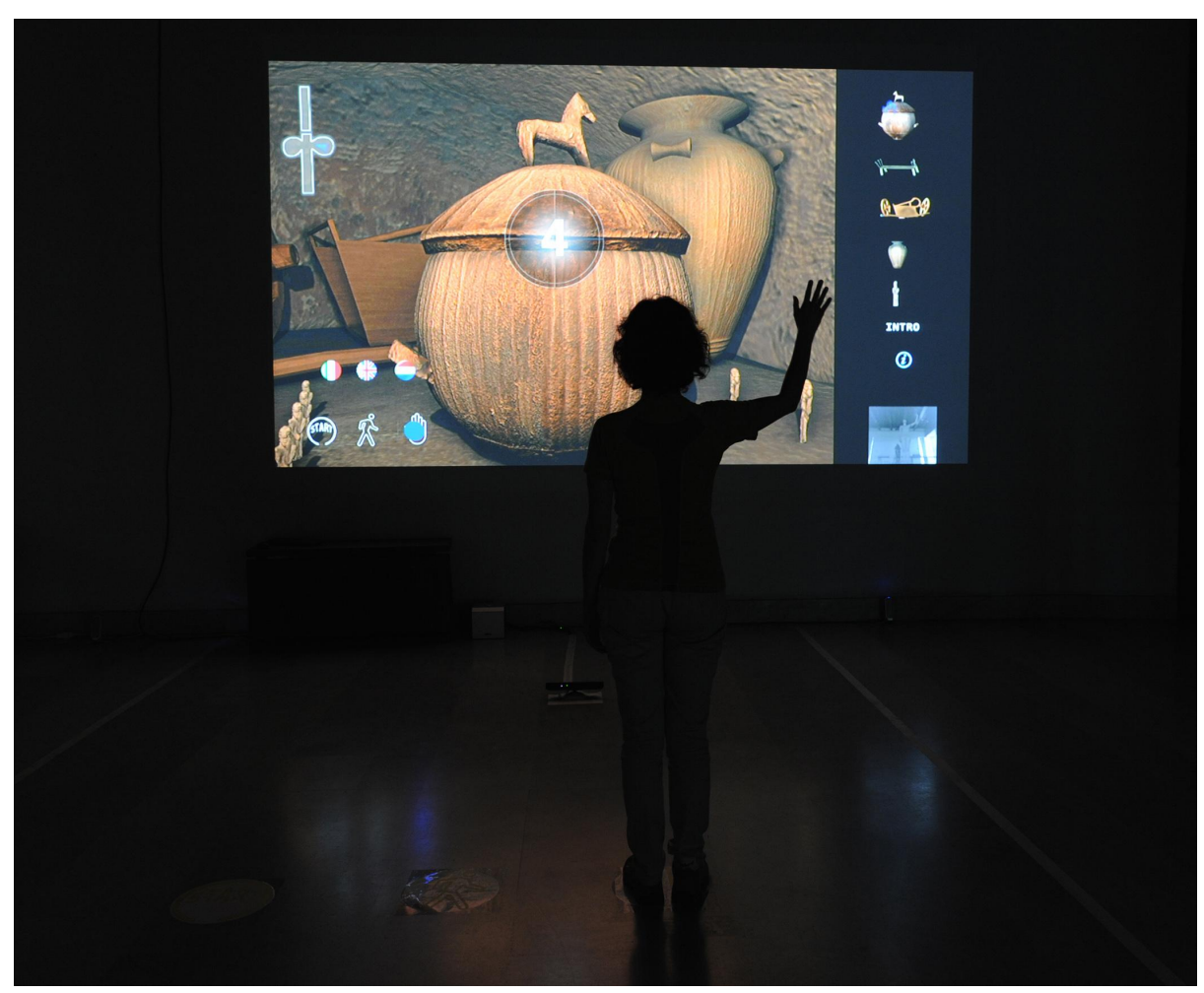

Figure 10. Etruscanning (2011-13). VR and gesture-based interaction, a permanent installation in the Vatican Museums related to the Regolini Galassi tomb, by CNR ITABC and E.V.O.CA. The figure shows the application presented at the Festival della Scienza in Genova in 2012.

Their presentations, as permanent installations in real museums or in temporary exhibitions, have been accompanied each time by studies of the users' experiences, which were fundamental in gaining an awareness of the efficacy of what was actually being done and what had to be improved, both from a technical and cognitive point of view. What generally emerged from all these surveys was that our efforts towards the creation of innovative approaches in storytelling, in visual moods, and in the multiplication of perceptive layers was obtaining successful results. The museum public is undoubtedly intrigued and attracted by technological solutions, but this attraction is ephemeral, as Kolb affirmed (cf. Section 1). The attention and the involvement, with respect to the contents, decrease easily and rapidly, especially when the experience is not assisted or accompanied by a human operator.

For this reason, we continue to explore more and more the topic of narration/dramatization inside interactive environments, combining different paradigms and techniques, in order to create a multisensorial and emotional experience favoring motivation and the learning process.

The Virtual Museum of the Tiber Valley first gave us the chance to limit the classic paradigms of virtual reality (the freedom of the user to go where he wants, more or less unconditionally) including other languages such as cinema, theatre (implying a specific direction in the camera movements, in 
the construction of the story and in the involvement of real actors), augmented reality and gaming (gesture-based interaction), in order to create a story inside a performative space.

In this VM, the landscape is represented in its complexity: (a) as the expression of multiple perspectives and values (geographical, historical, artistic, poetic, symbolic) evolved during different ages; and (b) from the observed to the interpreted and reconstructed landscape, up to the imagined and interiorized one (Fig. 11). The user can use his arms to swim, as a fish, in a underwater scenario, he can fly on a visionary landscape of the Tiber valley crossing places and ages, he can explore and walk as a man through the Roman Volusii's Villa and the Roman colony of Lucus Feroniae.
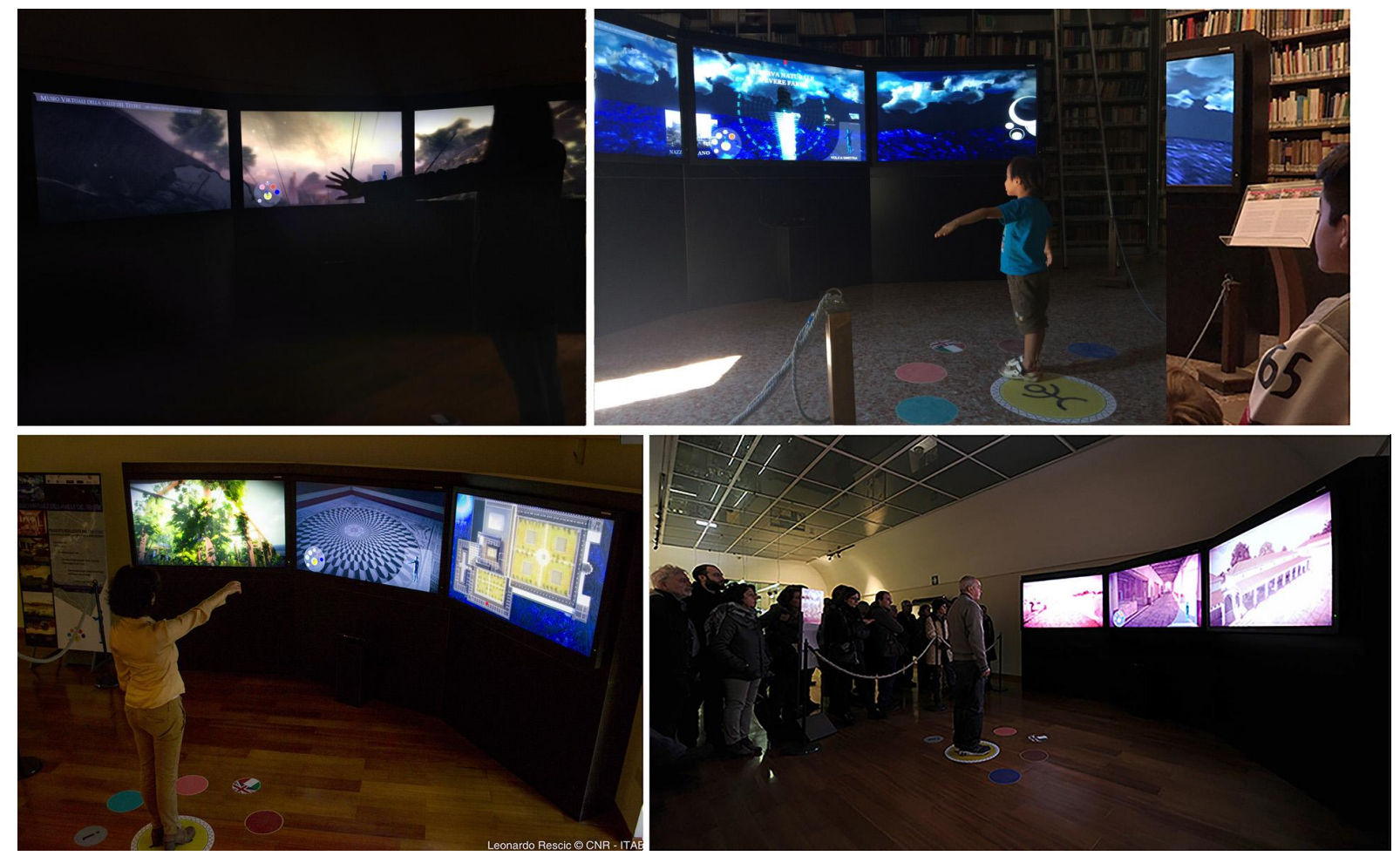

Figure 11. Virtual Museum of the Tiber Valley (2014). Permanent installation at the National Etruscan Museum at the Villa Giulia in Rome. The user interacts in 4 VR scenarios using body gestures; CNR ITABC and E.V.O.CA.

Similarly, Imago Bononiae [Fanini and Pagano 2105], offers another example of a performative urban space (Fig. 12). This gesture-based application allows the user to explore a large-scale 3D reconstruction of the city of Bologna in the Roman age (first century AD). Again, the visitor uses his body movements to interact in real time in the virtual scenario, performing a set of gestures in front of the projection [Fanini et al. 2015]. The urban environment is populated by a virtual crowd, controlled by artificial life algorithms and efficient interactive rendering techniques [Fanini and Calori 2013] [Schroeder 1997]. The crowd's behaviors, indeed, evolve along ancient roads and architectures, envisioning hypothetical paths, according to urban chronotopoi, and guiding the real users by means of color-coded itineraries towards different visions of the future urban layer of Bologna. 


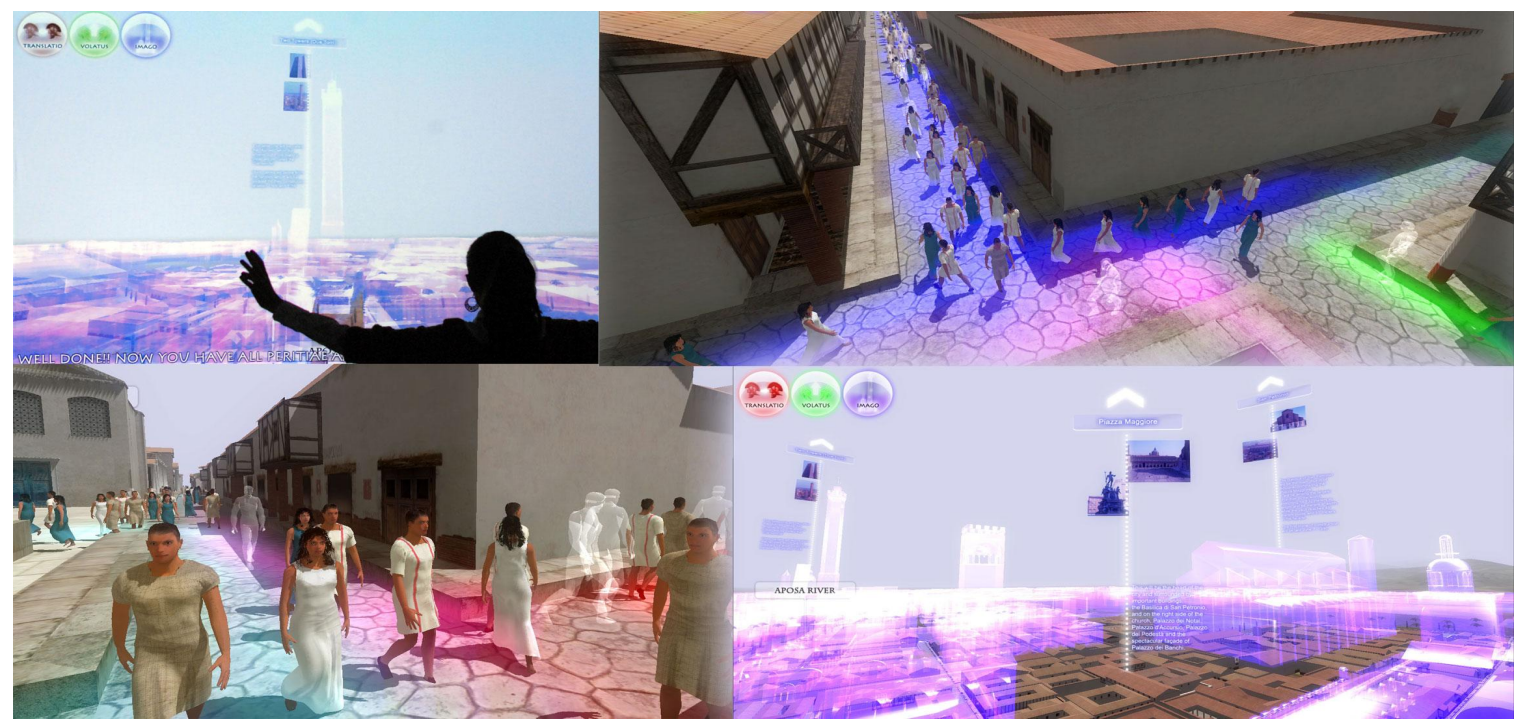

Figure 12. Imago Bononiae (2013). CNR ITABC in collaboration with CINECA.
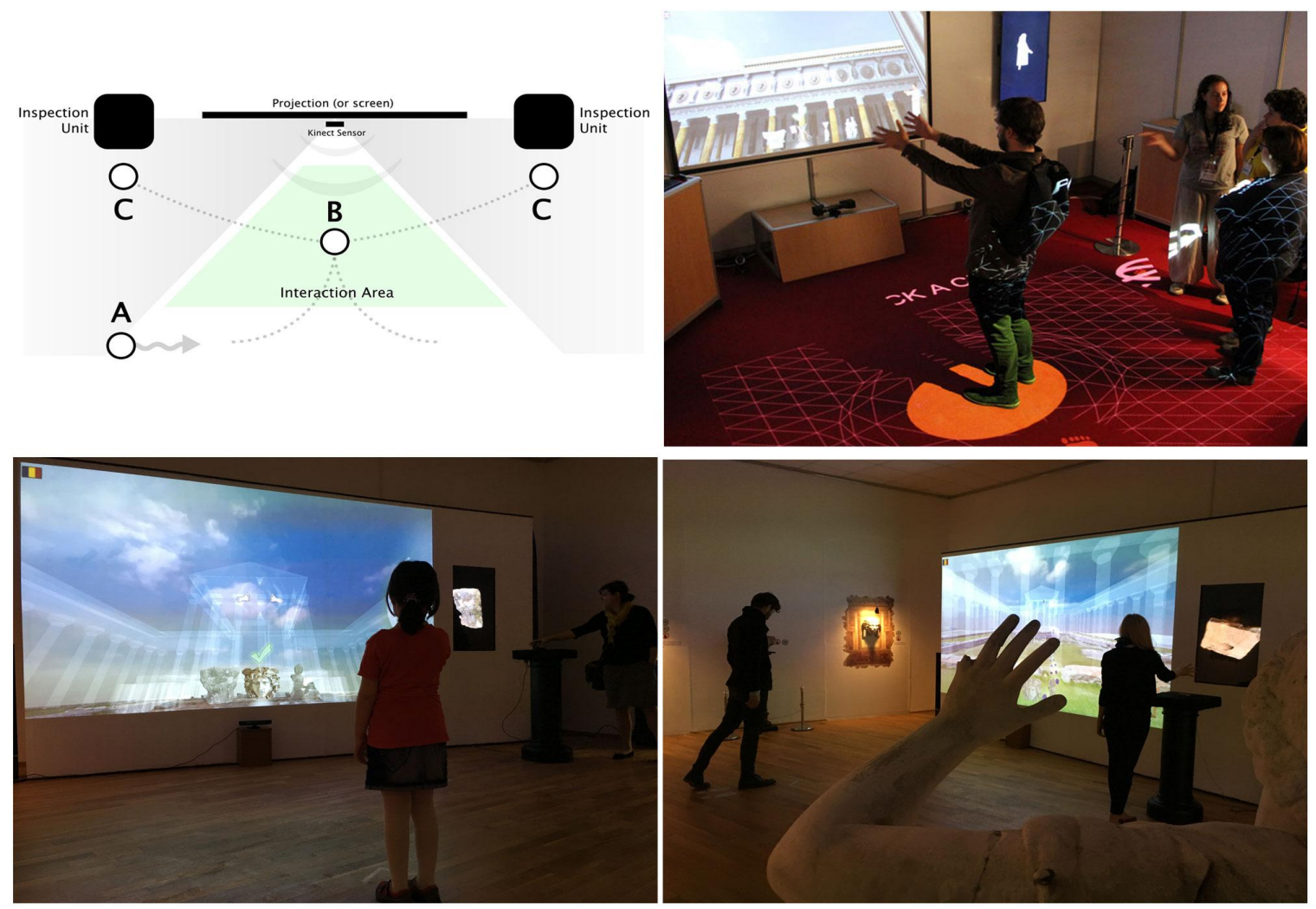

Figure 13. Admotum / AiRome (2015) with a complex setup using additional inspection units to enable shared gesture-based interactions among multiple players. CNR ITABC. 
Moreover, within the V-Must network, Admotum has been developed (Fig. 13). It is included in the temporary exhibition, "Keys to Rome," which allows visitors to virtually explore 3D reconstructed environments using body gestures partially similar to those used in Imago Bononiae (locomotion).

The game mechanics of Admotumare based on the idea of a treasure hunt, encouraging users to find and collect artifacts while exploring their original contexts. The modular nature of Admotum allows its reuse for different exhibits [Antal and Bota 2016] or, using more advanced interactions in a fully immersive setup, combining different sensors and creating a collaborative game play among multiple active visitors [Fanini et al. 2015].

After several experiments with natural interaction paradigms, CNR ITABC shifted toward a "simpler" but cognitively intriguing solution. The Box of Stories (Fig. 14), realized in the context of the European project CEMEC - Connecting European Early Medieval Collections (in progress). This is an installation conceived to be strictly connected to the museum's collections. It consists of a holographic showcase where the real artifact is shown inside it, and, thanks to the virtual projection on it and around it, the same museum object is brought back to life. The visitors can watch and listen to fragments of its story, evoking characters, events and voices. A drama takes place, not merely a description; thus, the visitors' experience is enhanced by means of detailed visualization, virtual restoration, contextualization, storytelling and dramatization of the object and about the object [Pietroni et al. 2017]. No physical interaction has been designed for this VM, but surely enhanced perception and narrative approach are the key issues from a cognitive point of view: we want to help the user to ideally abstract from the real museum and transfer its imagery into the original context of the object-the Avar period - so to understand how it was used, which were the beliefs around it, who was the owner, and so on.

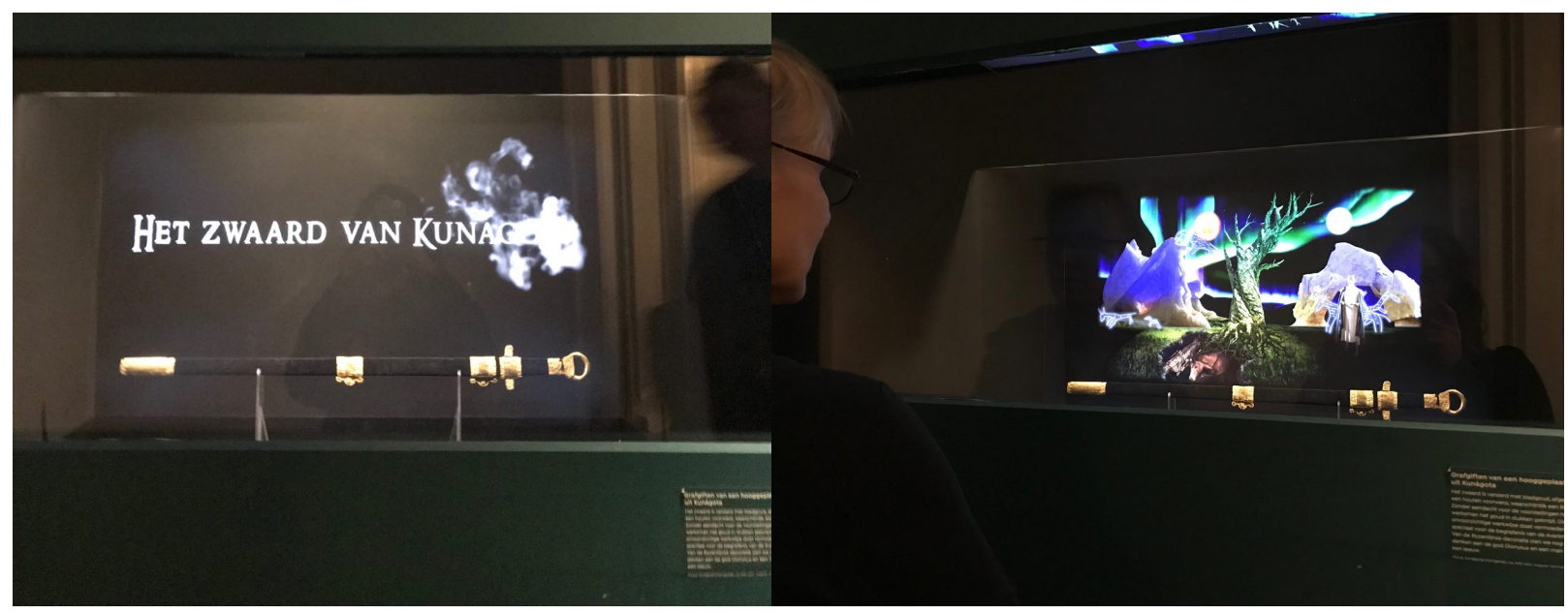

Figure 14. The Box of Stories (2018) at the Allard Pierson Museum of Amsterdam. CNR and E.V.O.CA. (CEMEC project).

Furthemore, parallel studies of CNR ITABC pertain to the immersive virtual reality (VR). Within this domain, an example is the ovrWalker application (Fig. 15), developed in 2015 as an effort to create a reusable, portable and scalable immersive explorer for Head-Mounted Displays (HMD). The project 
represents a further step toward the creation of a fully immersive experience inside reconstructed Virtual Archaeology environments that opens up new possibilities in terms of content dissemination and emotional fruition. The project has several objectives: (a) offering a full sense of presence inside virtual spaces (reconstructed or produced by range-based/image-based acquisitions), and (b) studying new user interfaces (for example, through the use of sensors) to interact with virtual environments for Cultural Heritage, in order to provide an ever more immersive and engaging experience for visitors in specific contexts of usage.

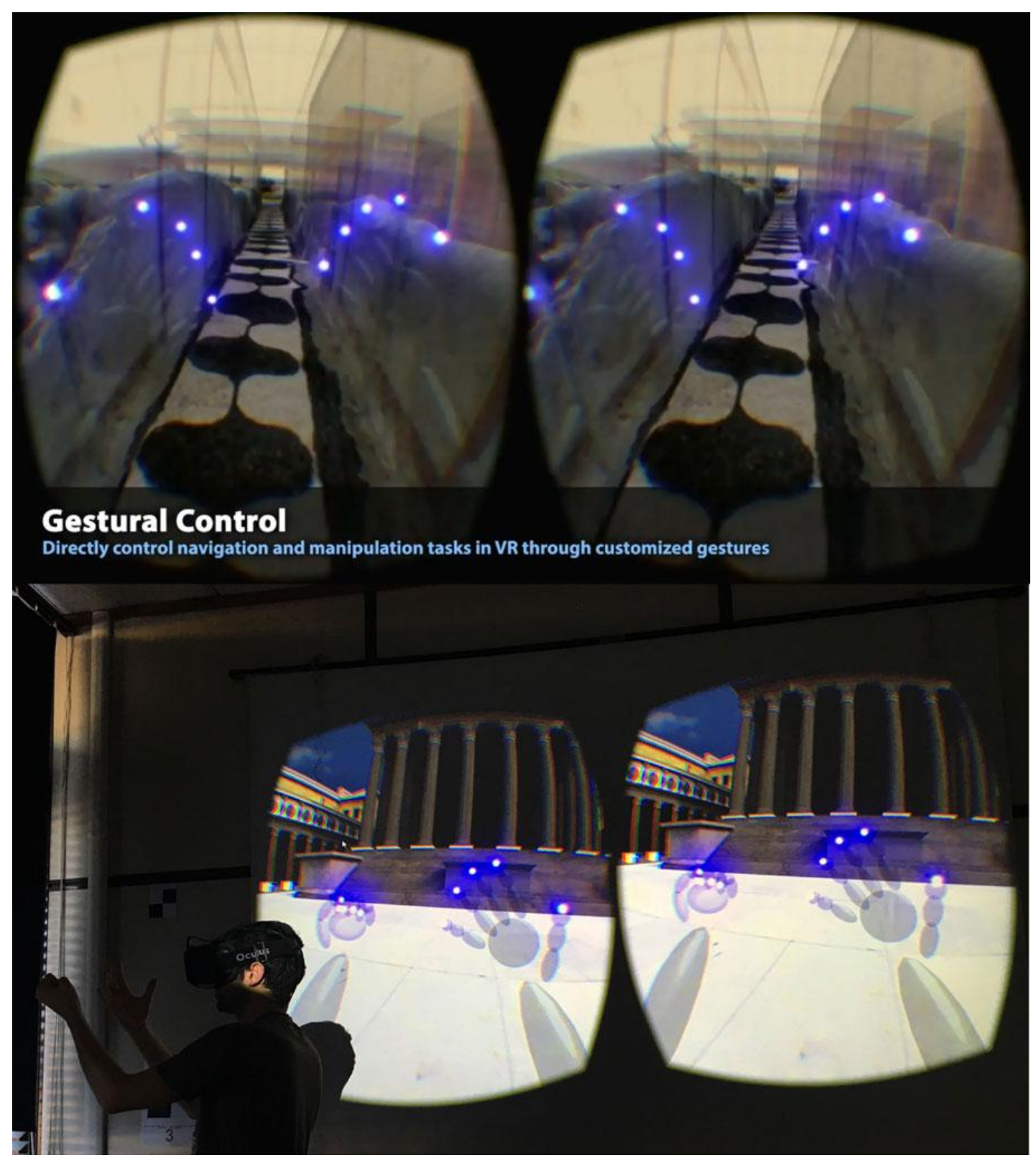

Figure 15. The "ovrWalker" experimentation with the Forum of Augustus, Rome, 2015. CNR ITABC. 


\section{UX DESIGN: FACTORS RAISING INTEREST IN IMMERSION AND EMBODIMENT}

As the VM projects showed, research in the field of sensory immersion into virtual worlds and emotional involvement is still in progress and never-ending. Even if the domain of VMs is rapidly evolving, it sometimes still inherits the same modus operandi of real museum contexts, taking with them the same mistakes and the same communication paradigms. But VMs are not simply the digital replicas of real museums. When dealing with communication following such an approach, we are in a cross-disciplinary domain, where science (content that must be transmitted), technology (the means allowing the transmission) and art (languages and forms adopted to solicit sensory and emotional engagement in the public) have equal importance. At least technologies and experimentation with communicative languages are in continuous evolution, and sometimes the contents may vary, if updated by the experts.

It is relevant to note the introduction, in the pipeline of work for the VM creation, of User Experience (UX) studies. This new investigative "step" allows experts and professionals to take advantage of concepts derived from sociology, psychology and educational fields and use them to deepen the knowledge about the emerging ICT domain. The results have been-and still are-promising for the future of technology-enhanced communication for Cultural Heritage.

UX studies are useful for investigating not only the technical features of the installations, but especially the content; what makes it understandable to people, what are the pedagogical advantages and the sense of involvement of people when exploring virtual worlds? The ease of investigation is not obvious. In the last two decades, several schools have begun to investigate the hedonic and pragmatic features of digital products, trying to build up an omni-comprehensive protocol of investigation, specifying the criteria of analysis and the methodology. However, VMs and their audiences have always been studied as separate worlds: whether analyzing the usability features of the former or the satisfaction of the latter; whether observing the overload of information of the first one rather than the level of memorization of the second. Thus, earlier attempts to evaluate such VM installations failed due to the lack of strategy in investigating the complexity of digital applications in terms of quantity and quality of contents and their accessibility. As a conclusion, "communicating" culture through the aid of advanced technology is not a technological issue, but an epistemological one [Gockel et al. 2013]: users' behaviors and the quality and quantity of the contents have influenced the overall experience and understanding.

Recently, the importance of cross-methodological studies has been accepted and also used by the academic sector - later than entrepreneurs and commercial domains-for their usefulness in the process of assessing the impact of such VMs. CNR ITABC has done a great deal of work in this field, developing a methodology of investigation called multi-partitioned analysis [Pagano and Cerato 2015] [Pagano et al. 2016] and focusing on cognitive aspects such as attention, memorization, and elaboration. Several user-experience evaluations and surveys have been carried out in the last ten years involving the public visitors to real museums and to VMs. Results showed what people actually perceive, once in front of a VM, what their emotions are, in which way(s) their senses are stimulated, and frequently, what they have learned about the content. Behaviors have also been observed, of both individuals and groups, and the feedback collected has given us new inputs for research.

Studies in Digital Heritage, Vol. 2, No. 1, Publication date: September 2018 


\section{2:28 E. Pietroni, et al.}

Generally, people appreciate feeling involved and embodied in a story; they want to live a sensory and lively experience [Pagano et al. 2016], which can happen if the storyline is well conceived and balanced along all the episodes. Thus, the narrative approach is the first factor raising interest towards a sense of engagement in the virtual world (section 4.1). Another important aspect, connected to the first, is the metaphor of interaction used by the system: in most cases and under certain conditions, people, usually studied in two categories-active or passive users [Pagano et al. 2016] -are comfortable in the role of the main "actor," who leads the virtual application. This is true especially in the case of natural interaction systems (NI), even if a sense of shame and embarrassment may occur. This aspect is also related to the level of attention paid by people towards the content of the VM: the active users, probably owing to the need to understand what to do, where to push or where to address their body gestures, are much more mentally alert than the passive ones, who generally remain seated, watching the scene in front of them. This obviously has an impact on comprehensibility and memorability of the information delivered by the VM, making the passive users more distracted and influenced by the contextual environment (section 4.2). A third factor raising the sense of immersiveness in VM is the graphic setup: the interface, the colors, the 3D and the sense of realism, the "magic" of images, the overall structure embracing the VM, and the characters (in the form of avatars or real actors). These are all aspects that have a specific weight in the development of the sense of engagement and embodiment of the users. Realism turns out to be something important but not essential; what actually plays a major role is the dramatization, the general atmosphere delivered through 3D graphics, visual moods and sounds. The same goes for stories where characters are personified by figures: real characters are preferred to avatars for the naturalness of the gestures, the oral dialogues and the movements. But this choice is not exclusive: according to the target group and the type of content, users may prefer cartoon-like characters and 2D imagery rather than something "overly" realistic. Finally, the context of use-case of the VM is the last relevant aspect to consider when designing and evaluating the user experience of visitors. One of the latest evaluations revealed that the same VM, experienced in two different contexts, collected different user-feedback as well as identifying problems needing to be faced [Pagano et al. 2018]. In the following sections, a deeper insight into several of the aspects just mentioned is presented.

\subsection{The narrative approach}

After several UX evaluations, it is clear that the descriptive approach has some limits, both from a content point of view and an emotional perspective. Firstly, it presumes that the target of the communication has a preliminary knowledge of, interest in and motivation toward the cultural information presented. We usually find an interest in what is already part of our lives and our feelings. In the absence of this condition, the description cannot easily reach the intended audience. Secondly, today we can access descriptive information regarding cultural items in catalogues, on the web and in online databases. This happens, for example, when we visit a church, a monument, or an historically interesting area: we use our mobile devices to search on the web and immediately we have the information. This condition allows us to get information tailored to the moment, on the specific occasion of visit; in this way, data cannot remain impressed in our memory for a long time, unless there is a strong interest behind it or a private interest.

Studies in Digital Heritage, Vol. 2, No. 1, Publication date: September 2018 
What makes up the user experience is thus the chance to let units of information be stitched into our minds; to do so, a favorable context of learning is needed. But how can we make it happen? The answer is that we must create a story that solicits the user's senses, accompanying him into a process of identification and making him feel comfortable in an augmented episode of life. In this way, the flow of associations between the virtual setting and the user's feelings, emotions and ideas can successfully be evoked, allowing his attention to be stimulated and memory to be activated. Feedback of this kind emerged in the UX evaluation of the Virtual Museum of the Tiber Valley and the Livia's Villa reloaded projects [Pietroni et al. 2016] as well as the Etruscanning 3D [Pagano et al. 2013].

In short, the experience of a VM has to produce a new piece of knowledge. With the term experience we usually identify a product, the sum of a series of factors, which includes perception, action, motivation, and cognition made into an inseparable, meaningful whole. An experience is thus "an episode, a chunk of time that one went through [...] sights and sounds, feelings and thoughts, motives and actions [...] closely knitted together, stored in memory, labelled, re-lived and communicated to others. An experience is a story, emerging from the dialogue of a person with her or his world through action" [Hassenzahl 2010] [Hassenzahl et al. 2010]. The contextual environment is something we create on our own for the majority of the time: we create the learning space needed for enculturation to take place, we open our feelings to it, we perform in it, we perceive it with our bodies and our minds [Gibson 1979]. In other words, we create the ground for a story to happen and this will be kept in our memory for a long time after. An experience is therefore subjective, holistic, situated, dynamic, and worthwhile [Hassenzahl 2011]. An example of this can be made to confirm the strong relation between emotional involvement and memorization. This is the case in a survey made in 2006-2007 at Giacomo Manzù Museum, in Ardea (Rome), of visitors following a guided tour. The majority of the people remembered one specific object of the exhibit: a chair with a basket of fruit above, without particular artistic value. This happened because the guide leading the tour presented that chair as the only object that Giacomo Manzù inherited from his father after his death, given the family's poverty. This episode raised awareness in the visitors, stimulating feelings of empathy, love, and sorrow for this poor family, finally causing this work of art to be remembered much more than others [Antinucci 2007]. This example, but also others cited as references, is unequivocal proof of the link between emotions and mind, senses and understanding: if we do not assimilate, starting from an impulse of curiosity and motivation, we cannot remember. Storytelling, interaction, emotional involvement and self-identification are thus all connected and play a fundamental role in the development of a learning experience [Pietroni and Adami 2014].

Even more than pure narration, dramatization can move the users' emotions and enhance their participation because the story is represented by characters, through dialogues expressing personal feelings and multiple perspectives, thus creating a dialectic. Much needs to be improved; being aware that this is a complex and articulated domain that requires difficult cross-disciplinary research, allowing a fruitful communication between designers and developers, but also with curators, museum professionals and artists. Unfortunately, cultural venues are often not yet ready to adopt such an emotional approach, but something is changing, at least in the Italian scene. 


\section{2:30 E. Pietroni, et al.}

\subsection{Interaction paradigms}

Interaction is a complex issue and it can be considered according to two different perspectives. First of all, people are usually favorable to interaction metaphors because they recall them as game-like conditions. They feel involved in the VM, playing as active users. In the usual sense, interaction is often associated with technology and innovation; for this reason, at the very beginning of any virtual experience, the VM (and its interactive mode) is attractive and it stimulates curiosity in the users. However, interaction can also be perceived as something frustrating, because it takes for granted that users already know how to manage the VM and that they have sufficient information about the proposed topic to be able to make choices. Thus, interactivity can be seen as a double mechanism: it first raises curiosity in all target groups, just for the pleasure of touching and pushing buttons or moving one's arms in front of a camera; but it can be a barrier for certain target groups, when it does not allow users to access information and start exploring, thus bringing about a sense of incompetence, sadness and embarrassment in them [Pagano and Pietroni 2017]. The success of the developers lies in the design of proper interaction interfaces, staying close to the natural behaviors of people. In the case of The Virtual Museum of the Tiber Valley (gesture-based interaction), the flight mode and the swim mode were very well appreciated by visitors, given the easiness of practice and the intuitiveness of the movements to be accomplished in making the VM work. The same goes for Admotum, where the paradigm of catching objects by simulating the grab gesture with the arms, greatly helped users in living an effective experience.

Furthermore, regarding this aspect, interaction needs to be well-calibrated and harmonized in the presence of a narration that traditionally develops throughout an established sequence of episodes or chapters. So, an efficacious interactive paradigm needs to be adopted together with the storyline [Ryan 2001]. Interaction should be perceived by the users as an "ally," something easy, clear and pleasant to perform. This issue sees the involvement of content developers, designers, and psychologists, who need to plan together the right gestures, according to the units of the story. In the case of Imago Bononiae, the gestures to be performed followed the game-growth of the user: as long as he reached specific abilities he could improve his gestures, following also a conceptual reward in terms of content accessibility (translatio, the ability to shift from one spot of the city to another one; volatus, the flight mode over the city of Bologna; imago, the visionary gesture of the city's future buildings).

While at the beginning of the experiments interaction was considered a key issue of technological research, today many museum applications are reconsidering this assumption in favor of an experience less interactive but more powerful in terms of sensory immersion and dramatization. Interaction, indeed, does not necessarily mean freedom for the user to make a choice in the virtual world, selecting a path or a content. Interaction can be experienced also at a cognitive level, when our communication paradigm establishes relations among several dimensions in multimodal way, for instance, creating an overlap between what actually and physically exists inside a museum or an archeological site, and other levels of virtual representation and visualization (mixed reality). Our minds are immediately involved in making comparisons, starting a process of progressive recognition, interpretation, and association, thus constructing the meaning. That is the main concept behind The Box of Stories project, where interaction takes place in the minds of the visitors all around the real object exposed (an Avar sword): the "magic" effects offered by the holographic technology,

Studies in Digital Heritage, Vol. 2, No. 1, Publication date: September 2018 
the dramatized storytelling about the original context of its use and its original owner, and the "original" soundscape, make reliving the Early Medieval period possible.

However, concerning interaction, two specifications need to be discussed in the following two sections: (a) natural interaction applications and the related level of immersion in the virtual world (section 4.2.1) that is conceived as full embodiment, and (b) the binocular perception implemented by head-mounted displays (section 4.2.2) that allow inclusion into the virtual world but also closure to the external (real) world stimuli. Lights, color grading, visual atmosphere, rhythm, camera movements, soundscape, velocity in movements...all these aspects immediately influence the feeling and the psychological condition of a person while he is using digital devices.

\subsubsection{Embodiment and Natural Interaction}

The user performs actions in the virtual environment by means of gestures and other body movements. This kind of interaction is considered as a sort of Natural User Interface (NUI). NUI refers to a class of user interfaces that enables the user to interact with a computer in a manner similar to how he interacts with the physical world, that is, through the use of his voice, hands and body. Gesture-based interaction models, specifically, may increase the overall embodiment if designed to correspond to common user interactions with the physical world, or when creating a "natural" mapping. A consistent example is the simulation of the swimming movements, corresponding, in the virtual world, with the identification of the user with a fish moving under the Tiber river waters: the user will naturally move his arms, opening and closing them as if he were really moving in the water. Another example is the flying ability in the Imago Bononiae project ("volatus"), where users can move their arms, mimicking a bird, to "take off" and perceive the urban layer from a different perspective.

In order to positively contribute to embodiment, in our project a set of user interface guidelines was considered during the interaction design phases. For instance, within Admotum and Imago Bononiae interaction models, some relevant guidelines have been drawn out:

- Remember your audience: the "grab" gesture in Admotum, for example, was designed to fit visitors with different arm lengths, thus allowing adults as well as children to interact with virtual items;

- Reduce degrees of freedom when possible: the user's movements inside the virtual environment are constrained, otherwise he will get lost or feel uncomfortable;

- Non-iosmorphic tehniques are useful and intuitive: in Admotum for instance, the visitor can reach distant and/or inaccessible objects with his/her virtual hands in order to empower abilities that would not be possible in real life;

- Remember that fatigue undermines gestures: try to keep the fatigue at a minimum, so that the virtual experience for the user is a pleasant moment along the museum visit path;

- Not much time should be spent by the user in learning the correct gestures to be performed; otherwise he will feel annoyed even before starting the virtual exploration. 
When dealing with NUI, the appropriate feeling is surely the embodiment [Forte and Bonini 2010] [Forte 2000]. From a technical point of view, embodiment is the physical process that uses the VR technology to project a person's body within the virtual world. A user can indeed see his hands or legs moving in the alternative reality, "touching" objects or "walking." From a cognitive point of view, in contrast, embodiment is the perception of one's total corporeal immersion into the VM (proprioception), being aware of the "separation" between a person's position in the real space and its corresponding position in the virtual one. The projection of one's body, or parts of it, is obviously an illusion, but this aspect turns out to be the source of our inclusive sensations [Tsakiris et al. 2010]: the person indeed recognizes himself as the cause of the actions and movements of that body in the corresponding virtual world. For a full sense of embodiment, visual, auditory, and haptic displays, together with a tracking system, are required to enable the system to deliver to the participant the illusion of being in a place. What is happening in such a place is considered plausible by him [Slater 2009]. In the absence of these conditions, the "magic" of being/experiencing another life in another world loses credibility, bringing the user to process that "reality" as ephemeral and not satisfying (Fig. 16).

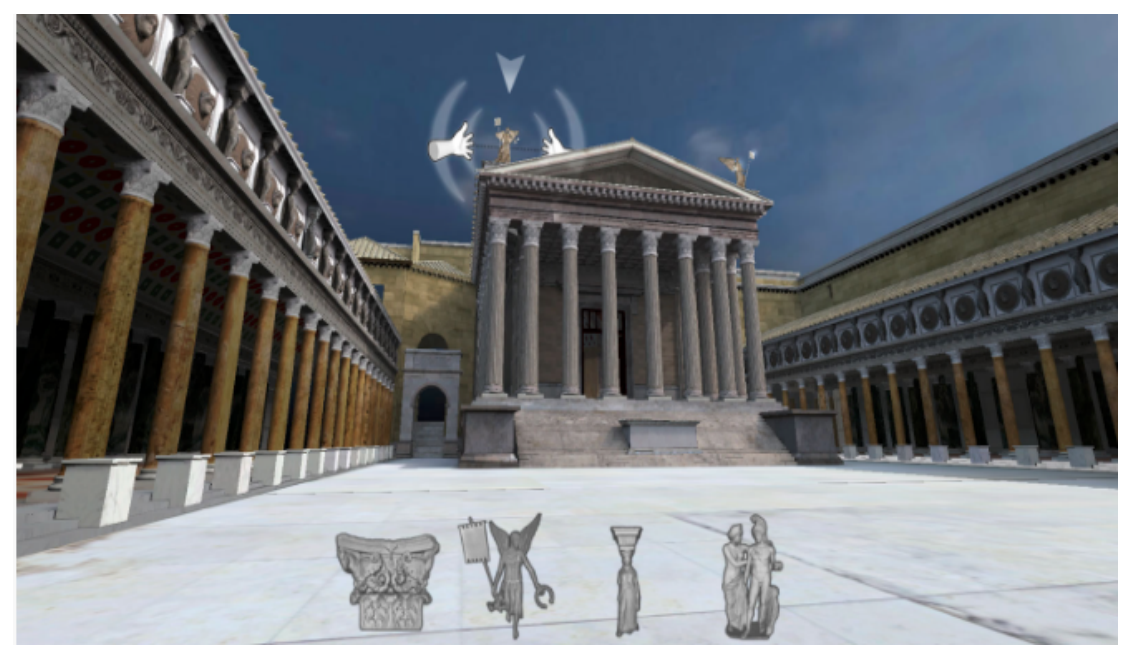

Figure 16. Example of NUI of Adomtum. The person's hands are replicated into the virtual world and are needed to provide the dimension of "grabbing" and collecting an object. CNR ITABC, 2015.

\subsubsection{Binocular perception}

The recent introduction of consumer-level Head-Mounted Displays (e.g.: Oculus Rift, HTC Vive, Samsung Gear VR, and others) may offer cheap means to create immersive experiences. A correct VR experience using full degrees of freedom for a head-orientation model is delivered by a 3D representation of a virtual environment. Owing to common knowledge and a vast literature on stereoscopic representation on HMDs, it is clear that factors such as IPD (interpupillary distance) and virtual environment scale can largely affect distance perception [Nguyen et al. 2011] and the user's sense of immersion. Regarding distance perception in HMDs with tracking systems, non-pictorial depth cues affecting immersiveness derive either from motion (motion parallax), the oculomotor 
system (convergence and accommodation), or binocular disparity. Within tracking systems, motion parallax represents an important depth cue for near-field objects, but its effectiveness declines with distance. Such research hugely impacts the way modern immersive experiences are crafted, in terms of content organization and effort.

Perceived distance plays an important role in HMD application [De Carvalho Souza and Dos Santos 2015] and specifically in the investigation of its compression. Several studies, in fact, have highlighted and demonstrated a well-known mismatch between perceived distances and modeled distances while wearing an HMD. Previous research reviews and evaluations report underestimations of spatial dimensions at about $74 \%$ of actual modeled dimensions [Renner et al. 2013] [Ebrahimi 2015], while recent works focus on the importance of visual cues and how they impact perception accuracy [Loyola 2017]. Owing to its importance for executing interactive tasks, distance perception in HMDs did prove its crucial role and how this affected application development and interaction models, especially regarding correct distance judgment.
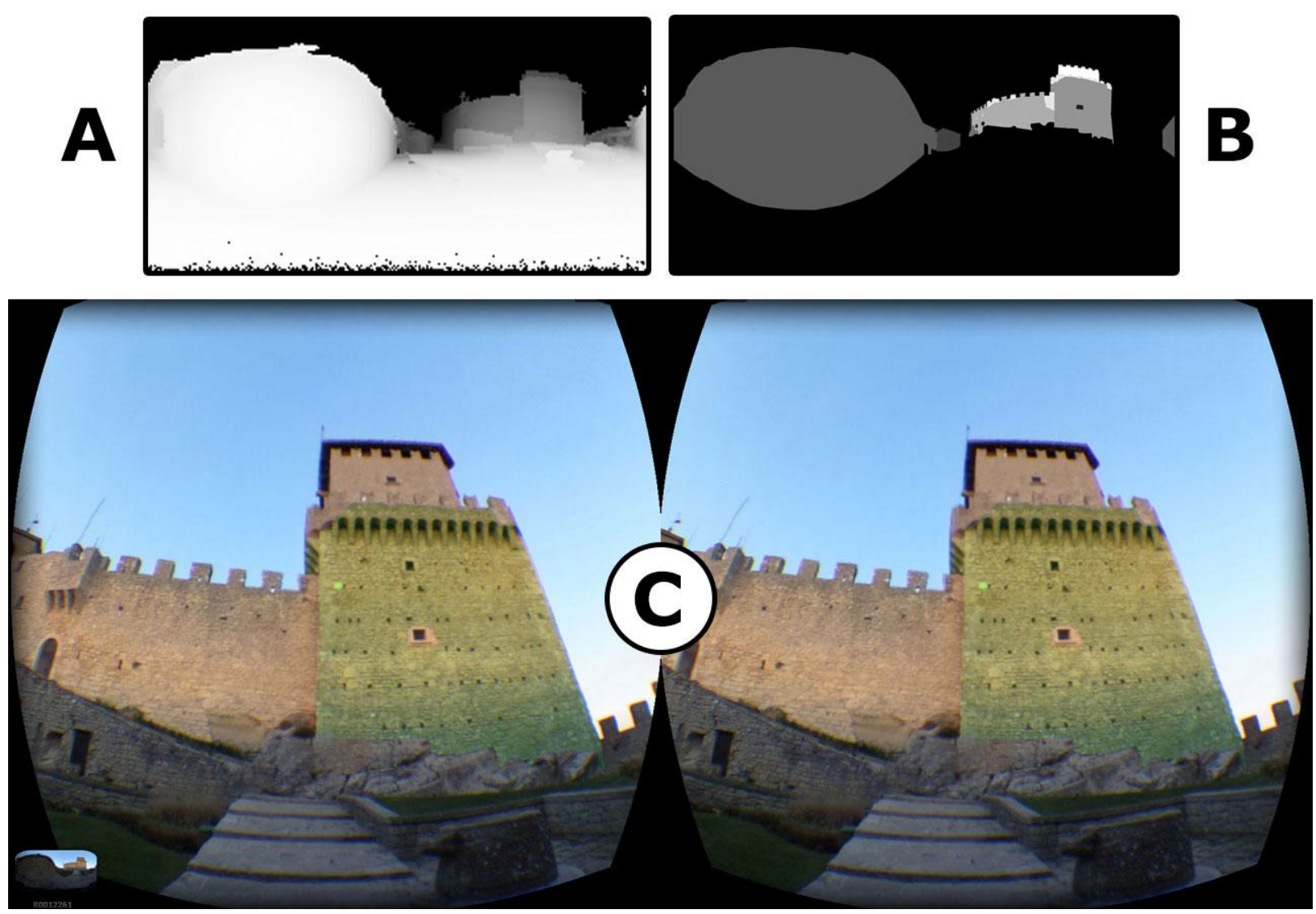

Figure 17. An example of HMD fruition through the use of a DPF (Depth Panoramic Frame) data model, encoding non-linear depth $(A)$ in order to approximate original depth perception $(C)$ and semantic information $(B)$ through encoded masks. Dissemination is performed through a common web browser. 
Distance perception in HMDs is also the core topic of some recent studies on interactive application of egocentric virtual environments - i. e., immersive use from a single location (e. g., panoramic datasets) - and how to deliver them in a compact manner. Several implementations suffer, in fact, from monoscopic perception (constant egocentric distance deployed, for instance, by common 360 panoramas) "downgrading" the whole experience in relation to modern HMD capabilities. On the other hand, common pitfalls and mismatches in stereoscopic egocentric data models (e. g., common stereoscopic 360 panorama pairs) [Bourke 2006], lead to motion sickness and eye strain. Few solutions in recent works [Fanini and d'Annibale 2016] aim to restore correct depth perception in HMDs through the use of non-linear omnidirectional depth maps, considering the stereoscopic accuracy of the human eye. Such an approach offers a compact data model that encodes original depth, suitable for web-based dissemination of static or dynamic (video-stream) egocentric datasets (Fig. 17).

\section{SOFTWARE DEVELOPMENT: A CROSS-FERTILIZATION RESEARCH}

Referring to immersion and embodiment in VM applications, several challenges are raised for software developers, going beyond mere performance, optimization and workflow considerations, in order to package an effective immersive experience. Such a road presents a wide range of issues, especially when it encounters serious gaming and virtual archaeology, thus including 3D assets and virtual reconstruction validation (i.e. columns, temples, fountains).

Today's modern game engines (e. g. Unity, Unreal Engine, CryEngine, etc.) and additional ad hoc tools offer several options to a multi-disciplinary team for building up credible effective virtual worlds with complex interaction paradigms, as well as flexible, agile and iterative pipelines of work. 3D assets ingestion (dataset inclusion in the virtual world), scene dressing (texturing, coloring and character population) and optimization for real-time visualization are much easier today than they were five or more years ago, thus removing some bottlenecks in application development. A natural consequence of iterated cycles of application or installation deployment is the crafting of modular software containers, able to suit local museum requirements or specific customizations [Fanini et al 2015]. Such approaches offer a multi-disciplinary team a way to create reusable software components, facilitating and boosting development and deployment processes, as well as reducing the costs for cultural institutions that are planning to host VMs in their spaces.

Regarding the development of gesture-based applications, the software has to be equipped with a gesture recognition system through the use of a sensor (i.e. Microsoft Kinect, Leap Motion, etc.), which allows the developer to map the user's physical movements into a set of predefined actions. Unlike standard devices, like a keyboard or mouse, such sensors allow spatial tracking of specific joints of a human body (i.e. arms, hands, shoulders, fingers, etc.) within a 3D environment (Fig. 18). These joints are generally enclosed in sequential frames over simulated time, providing, for instance, 3D positions $<\mathrm{X}, \mathrm{y}, \mathrm{Z}>$, motion data, and orientation for each joint. 


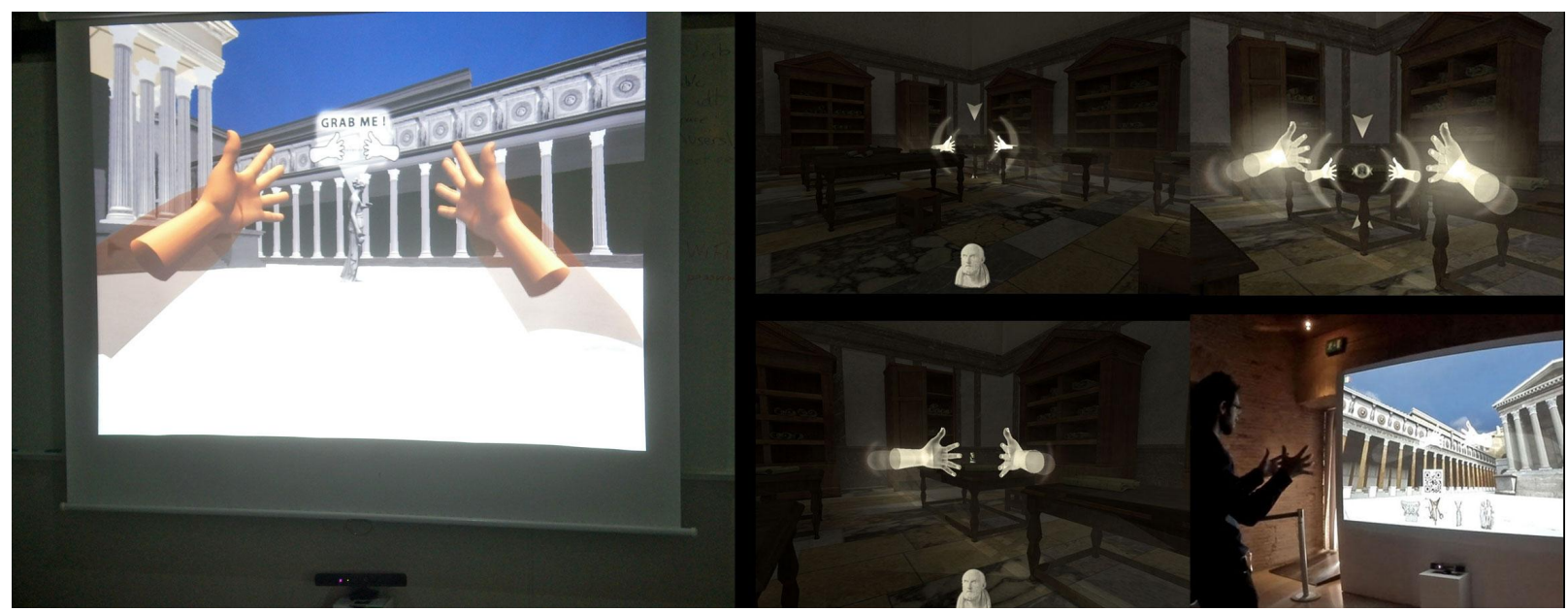

Figure 18. The grab gesture in Admotum: from prototypes to final deployment.

On the application side, the developer's main efforts consist in the creation of a software layer that processes incoming data. The role of such a layer is to efficiently recognize specific patterns (gestures) over an observed time slice (a set of frames), thus converting incoming spatial inputs into direct actions inside the virtual environment. In this way, the sense of bodily inclusion into the virtual world is also immediate for the developer who is testing the VM application: this allows him or her to notice any occurring error clearly and adjust it quickly.

Binocular immersive perception, Head-mounted Displays (HMDs) and immersive VR may deliver truly inclusive experiences under certain circumstances. They can take advantage not only of immersive visualization but also of sounds, through integrated earphones and haptic tools. Nevertheless, from the visualization side, owing to rendering demands on such devices, special attention is required to manage the level of detail of the 3D scene, in order to make it credible and pleasant for users, while simultaneously improving the sense of total embodiment. Also, features like stereoscopic visualization and interactive rendering at very high frame-rates (commonly targeting 90fps) are crucial from a software development perspective. An unbalanced workflow, including bad practices, may negatively affect the final result and the overall immersive experience.

Merely having an efficient visualization or an optimal frame-rate is, of course, not sufficient alone to offer a sense of presence in the virtual world and the related sense of immersion. Well-designed user interfaces and interaction models with 3D virtual contexts vastly affect final user experience. Within wearable devices or sensors operating in a physical space, 3D interfaces are commonly employed to provide a layer that allows users to perform various tasks directly in a 3D spatial context [Bowman et al. 2001]. Since 3D interaction is a fairly recent topic, the maturity of 3D interface design principles lags behind those for standard GUIs. Given the wide diversity of input devices and interaction models, currently there is no established standard for 3D User Interfaces. While general Human Computer Interaction (HCI) principles such as Nielsen's heuristics [Nielsen and Molich 1990] still apply, they do not suffice in designing a usable 3D UI for the software application. 


\section{2:36 E. Pietroni, et al.}

\section{CONCLUSIONS}

Through the use of Virtual technology, a multidisciplinary team can recreate a dynamic space that includes not only real cultural objects but also relationships, where the user can perform activities and create a "visual drama" beyond what he can see. In this scenario, VMs involve learning stages.

From the above-presented experiments, we have demonstrated how the attention of academic and research fields has been, from the very beginning, less focused on the hedonic aspects (such as emotions, senses, perception, and environmental atmosphere) and more on technicalities like digitization, software automatization and usability. However, the former features have a precise and crucial role in the meaning-making of the world around us, as were revealed by several UX evaluations. Therefore, the need for deepening our studies of communication paradigms is highly felt. This is something very complex and problematic, because it implies a cross-disciplinary approach among the working team as well as a constant relationship with the audiences of VM projects, the main target of our communication.

The design of a good UX poses a great challenge for both designers and developers. It requires the reflection on certain key factors: the context of use, the environmental conditions (silent or noisy, dark or illuminated, secluded or crowded), the target age and provenience, the conditions of content accessibility, the time of usage, the possibility of intervention on the physical space hosting the installation, the expectation of the museum and so on. All of these aspects must influence the conceptual structure of the VM. "Must" here is stressed because it is not feasible in the 21st century to design and develop a VM for cultural venues without considering the final users and their emotional needs and status-whether they are lay people, or experts, or professionals. Consequently, the style of the storytelling, the interaction interface, the sense of embodiment, the choice of technology and the appropriate software architecture derive from the above-mentioned issues.

Technology is a tool that helps us to shape a sense of involvement in the real as well as in the digitally augmented world. The public is usually attracted by new technological solutions, which also receive great attention from the promotional media. However, several surveys that we have carried on inside museums or exhibitions observing people's behavior, have very clearly shown that attention to tools and devices is not long-lasting. It rapidly decreases if the cultural and perceptive contents are not able to keep it alive and, similarly, if the interaction is difficult and not natural. For these reasons, it is necessary to rethink technologies at a deeper level of usage, in order to (a) match them with the spheres of emotions and knowledge - as in Bloom's Taxonomy - and (b) strengthen the fruitful collaboration between academics (both in the field of ICT and also the humanities), museum staff, artistic domain, and the general public.

The emotional component is fundamental in the VM experience because it is the "irrational" part of every human being, and it generates motivation, the first impulse that pushes people to encounter technological solutions and lets the learning process take place. In the 1990s, Daniel Goleman introduced the concept of Emotional Intelligence (EI), the ability of individuals to recognize their own emotions and those of others, distinguishing between different feelings, using emotional information to guide their thinking and behavior, and managing emotions to adapt themselves to the surrounding environments or to achieve a specific goal [Goleman 1995]. Following this theoretical approach, it goes without saying how important it is that EI be considered when designing the user

Studies in Digital Heritage, Vol. 2, No. 1, Publication date: September 2018 
experience of a VM. All of us, indeed, explore the world around us and relate our feelings and emotions to what we are doing - it is the learn-by-doing model of Kolb. Emotions act as receivers for collecting information about relationships, behaviors and every aspect of human life. Having once captured all such information, our mind starts processing and including it into a grid of past experiences. In this way, we are able to shape new knowledge on the basis of the previous experiences already collected (experiential knowledge) and to react to the environment around us relying upon the lessons learnt [Gianni Falvo 2015]. If we think about VMs, this process of managing emotions and senses works the same way.

Recent research in the fields of art and culture [Gianni Falvo 2016] has shown that emotions are constructive and contribute to enhanced performance and better decision-making of people who have visited a cultural venue. This opens up two considerations: (a) the importance of information redundancy, and (b) the sound component in real museums. Concerning the former, the same content can recur several times in the communicative plan, with variations, so as to multiply and imprint its meaning in the receiver's mind. Any redundancy must therefore not be merely the same; otherwise it becomes annoying and demotivating. Regarding the latter, the prevalence of visual components in museums depends on the evolution of technology. The challenges of visualization with computers, and the role of photography first and cinema later, have meant for sound a more limited evolution and inclusion into VM projects. According to Goleman, even if it is true that emotions strongly contribute to our thinking, we cannot avoid considering music and environmental sounds for our understanding of the world.

We firmly believe that the cooperation between museum staff, researchers, content curators, cognitive scientists, anthropologists, educators, computer scientists, artists, directors, designers, set designers, musicians and technicians should be recommended and promoted. This is meant to create something new and powerful for cultural transmission, integrating real and virtual museums to achieve a greater sense of presence in the story. The future challenge for UX designers and software developers is to reduce the gap between the fictional virtual world and human behavior, thus allowing a more natural interaction, even if natural is closer to the concept of intuitive here. New research must be shifted onto a perceptive sphere, both from a content point of view and from a technical point of view, in order to limit cognitive mistakes and to ensure users' comfort as they experience a VM.

\section{REFERENCES}

AA. VV. 2000. I critofilm di Carlo Ludovico Ragghianti, GAM/Galleria civica d'arte moderna e contemporanea, Turin.

Adriana Antal, Emilian Bota. 2016. "A complete workflow from the data collection on the field to the deployment of a Virtual Museum: the case of Virtual Sarmizegetusa".

Francesco Antinucci. 2007. Musei Virtuali, Laterza, Roma.

Francesco Antinucci. 2014. Comunicare nel Museo, Laterza, Roma. 


\section{2:38 E. Pietroni, et al.}

Rudolf Arnheim. 1954. Arte e percezione visiva. Campi Del Sapere, Feltrinelli, 2008, ISBN 9788807100239.

Gregory Bateson. 1972. Steps to an Ecology of Mind, San Francisco.

Gregory Bateson. 1979. Mind and Nature: a Necessary Unit, New York, Dutton.

Frank Biocca. 1997. The Cyborg's Dilemma: Progressive Embodiment in Virtual Environments. J. Comput. Commun. 3, 2 (1997), https://doi.org/10.1111/j.1083-6101.1997.tb00070.x

Paul Bourke. 2006. Synthetic stereoscopic panoramic images. In Interactive Technologies and Sociotechnical Systems. Springer. Berlin, Heidelberg, 2006.

Doug A. Bowman, Ernst Kruijff, Joseph J. LaViola. 2001. An introduction to 3D user interface design. Presence: Teleoperators and Virtual Environments, 10, 1 (2001), 96-108.

Cesare Brandi. 1963. Teoria del restauro.Piccola biblioteca Einaudi. Milano.

Michel Cabanac. 2002. What is emotion? Behavioural Processes 60, 2 (2002), 69-83. https://doi.org/10.1016/S0376-6357(02)00078-5

Fiona Cameron, Sarah Kenderdine. 2007. Theorizing Digital Cultural Heritage. A Critical Discourse, Cambridge.

A. M. de Carvalho Souza and S. R. dos Santos. 2015. Investigating the distance compression on virtual environments by comparing visualization devices. In Virtual and Augmented Reality (SVR), 2015 XVII Symposium on, 33-41. IEEE.

Lorenzo Cuccu. 2003. Cinema e pittura nell'esperienza teorica e critica di Carlo Ludovico Ragghianti, in Cinema/Pittura dinamiche di scambio a cura di L. De Franceschi, Lindau, Turin, Università degli Studi Roma Tre.

John Dewey. 1938. Experience \& Education. New York, NY: Kappa Delta Pi. ISBN 0-684-83828-1.

Bruno Fanini and Alfonsina Pagano, 2015. Interface design for serious game visual strategies: the case study of "Imago Bononiae". In Proceedings of Digital Heritage 2015, International Congress, 2015, Granada, Spain, IEEE Press.

Bruno Fanini, Alfonsina Pagano, Emanuel Demetrescu., Enzo d'Annibale, Daniele Ferdani. 2015. Engaging and shared gesture-based interaction for museums: The case study of K2R international Expo in Rome. In Proceedings of Digital Heritage 2015, International Congress, International Congress, 28 ottobre - 2 ottobre 2015, Granada, Spagna, IEEE Press.

Bruno Fanini, Enzo d'Annibale. 2016. A framework for compact and improved panoramic VR dissemination. Proceedings of the 14th Eurographics Workshop on Graphics and Cultural Heritage. Eurographics Association.

Bruno Fanini, Luigi Calori. 2013. 3D Interactive Visualization of Crowd Simulations at Urban Scale. In Proceedings of 9th Congress "Virtual Cities and Territory", Rome, 2-4 October 2013.

Maurizio Forte, Elena Bonini. 2010. Embodiment and enaction: a theoretical overview for cybercommunities. "Heritage in the Digital Era", 45-56, Multi-science Publishing Co. 
Maurizio Forte. 2000. About virtual archaeology: disorders, cognitive interactions and virtuality, in J. A. Barceló, M. Forte \& D. H. Sanders (eds.), Virtual Reality in Archaeology, B.A.R.

Vittorio Gallese, 2005. Embodied simulation: From Neurons to Phenomenal Experience, in Phenomenology and the cognitive sciences.

Mario Gerosa. 2007. Second life, Meltemi ed. Roma.

Perla Gianni Falvo. 2015. Exhibit design with multimedia and cognitive technologies, impact assessment on Luca Giordano, Raphael, the Chapel of the Magi in Palazzo Medici Riccardi, Florence. In Proceedings of Digital Heritage 2015, International Congress, International Congress, 28 ottobre 2 ottobre 2015, Granada, Spagna, IEEE Press.

Perla Gianni Falvo. 2016. A Virtual itinerary for a real experience. The Frescoes of the Chapel of the Magi in Palazzo Medici Riccardi, Florence. SCIRES - SCIentific RESearch and Information Technology. Vol. 6 No. 1 (2016), 41-50, e-ISSN 2239-4303.

James Jerome Gibson. 1979. The ecological approach to visual perception. Houghton Mifflin, Boston.

Bianca Gockel, Joakim Eriksson, Holger Graf, Alfonsina Pagano, Sofia Pescarin., 2013. VMUXE - An Approach to User Experience Evaluation for Virtual Museums. In Proceedings of The HCI International 2013, 21 - 26 Luglio 2013, Las Vegas, Nevada, USA, Ed. Springer, Heidelberg.

Ian Gold. 2001. Perception: Philosophical Aspects. International Encyclopedia of the Social \& Behavioral Sciences, pp. 11209-11215.

Daniel Goleman. 1995. Emotional intelligence: why it can matter more than IQ. London: Bloomsbury.

Marc Hassenzahl. 2010. Experience Design: Technology for All the Right Reasons. Morgan and Claypool Publishers.

Marc Hassenzahl, Sarah Diefenbach, Anja Göritz. 2010. Needs, affect, and interactive products Facets of user experience, In Interacting with Computers.

Marc Hassenzahl. 2011. User Experience and Experience Design, in interaction-design.org.

Tim Ingold, 2000. The perception of the Environment. Essays in livelihood, dwelling and skill, London and New York.

Robert Loo. 2002. A Meta-Analytic Examination of Kolb's Learning Style Preferences Among Business Majors. Journal of Education for Business.

Mauricio Loyola. 2017. The influence of the availability of visual cues on the accurate perception of spatial dimensions in architectural virtual environments. In Virtual Reality (2017): 1-9. International Series 843, Oxford: Archaeopress: 247-263.

Humberto Maturana, Francisco Varela. 1980. Autopoiesis and Cognition: the Realization of the Living, in Boston Studies in the philosophy of science, 42.

D. Mellet d'Huart, 2006. A Model of (En)Action to approach Embodiment: A Cornerstone for the Design of Virtual Environments for Learning, in Win-Hedley. 


\section{2:40 E. Pietroni, et al.}

Sharan B. Merriam, Rosemary S. Caffarella, Lisa M. Baumgartner. 2007. Learning in adulthood: a comprehensive guide, San Francisco.

Tien Dat Nguyen, Christine J. Ziemer, Timofey Grechkin, Benjamin Chihak, Jodie M. Plumert, James F. Cremer, Joseph H. Kearney. 2011. Effects of scale change on distance perception in virtual environments. ACM Transactions on Applied Perception (TAP).

Jakob Nielsen and Rolf Molich. 1990. Heuristic evaluation of user interfaces.In Proceedings of CHI 90, pp. 249-256. New York, NY: ACM.

Alfonsina Pagano, Daniele Ferdani, Eva Pietroni, Gergely Szenthe, Szilvia Bartus-Szöllősi, Assunta Sciarrillo, Enzo d'Annibale. 2018. The box of stories: user experience evaluation of an innovative holographic showcase to communicate the museum objects. In Proceedings of the International Forum held at the State of Hermitage Museum, Saint Petersburg. The State Hermitage Publishers, 2018, 163-178. ISBN: 978-5-93572-792-5

Alfonsina Pagano, Eva Pietroni. 2017. Un metodo integrato per valutare i Musei Virtuali e l'esperienza dei visitatori. Il caso del Museo Virtuale della Valle del Tevere. Atti del workshop, 15 dicembre 2016, Edizioni CNR - Ottobre 2017, Roma, ISBN 9788890202834.

Alfonsina Pagano, Eva Pietroni, Caterina Poli. 2016. An integrated methodological approach to evaluate virtual museums in real museum contexts. In Proceedings of the 9th annual International Conference of Education, Research and Innovation (ICERI), Seville, Spain, 14-16 November 2016, ISBN: 978-84-617-5895-1.

Alfonsina Pagano, Eva Pietroni, Claudio Rufa. 2013. The Etruscanning project: Gesture based interaction and user experience in the virtual reconstruction of the Regolini Galassi tomb. In Proceedings "Digital Heritage 2013", International Congress, October 28 - November 1st 2013, Marsiglia, Francia, IEEE Press.

Alfonsina Pagano, Ivana Cerato. 2015. Evaluation of the educational potentials of interactive technologies applied to Cultural Heritage. The Keys To Rome exhibition case study. In Proceedings "Digital Heritage 2015", International Congress, September 28 -October 2 2015, Granada, Spain, IEEE Press.

Jaak Panksepp. 2005. Affective neuroscience: the foundations of human and animal emotions. Oxford University Press.

Erwin Panofsky, 1996. Il significato nelle arti visive. Piccola Biblioteca Einaudi. Milano, ISBN 9788806205614.

Sofia Pescarin, Eva Pietroni, Mattias Wallegard, K.Omar, Leonardo Rescic, Claudio Rufa. 2013. NICH Natural Interaction in the Cultural Heritage domain: a preparatory study on cross-cultural natural gestures, in Proceedings of Digital Heritage International Congress 2013, IEEE Advanced Technology of Humanity.

Eva Pietroni, Andrea Adami. 2014. Interacting with Virtual Reconstructions in Museums: The Etruscanning Project, in Journal on Computing and Cultural Heritage (JOCCH), Special Issue on Interacting with the Past. 
Eva Pietroni, Enzo d'Annibale, Daniele Ferdani, Massimiliano Forlani, Alfonsina Pagano, Leonardo Rescic, Claudio Rufa. 2017. Beyond the Museum's object. Envisioning stories. In Proceedings of the 9th International Conference on Education and New Learning Technologies.

Eva Pietroni, Alfonsina Pagano, Marco Amadei, Federica Galiffa, 2016. Livia's Villa Reloaded virtual museum: user experience evaluation. In Proceedings ICERI 2016, 9th annual International Conference of Education, Research and Innovation, Seville, Spain, November 2016, 349-359. ISBN: $978-$ 84-617-5895-1, doi: 10.21125/iceri.2016.1083.

Carlo Ludovico Ragghianti. 1974 . Arte, fare, vedere. Dall'arte al museo, Vallecchi, Firenze.

Carlo Ludovico Ragghianti. 1975. Arti della visione. Giulio Einaudi Editore, Milano.

Rebekka S. Renner, Boris M. Velichkovsky, Jens R. HelmertPublished. 2013. The perception of egocentric distances in virtual environments-a review. ACM Computing Surveys (CSUR) 46.2 (2013): 23.

Marie-Laure Ryan. 2001. Narrative as Virtual Reality: Immersion and Interactivity in "Literature and Electronic Media", Baltimore and London, Johns Hopkins University press, HB.

Daniel Schacter. 2011. Psychology Second Edition. 41 Madison Avenue, New York, NY 10010: Worth Publishers. p. 310. ISBN 978-1-4292-3719-2.

Ralph Schroeder, 1997. Networked Worlds: Social Aspects of Multi-User Virtual Reality Technology, in Sociological Research Online, 2, 4.

Vittorio Sgarbi, 2002. Il Bene e il Bello: la fragile condizione umana; in collana Assaggi Bompiani.

Mel Slater. 2009. Place illusion and plausibility can lead to realistic behaviour in immersive virtual environments. Philos. Trans. R Soc. Lond. B Biol. Sci. 364, 3549-3557. doi:10.1098/rstb.2009.0138

Robert J. Sternberg, Karin Sternberg. 2009. Cognitive psychology, Belmont, CA.

Manos Tsakiris, Lewis Carpenter, Dafydd James, and Aikaterini Fotopoulou. 2010. Hands only illusion: multisensory integration elicits sense of ownership for body parts but not for non-corporeal objects. Exp. Brain Res. 204, 343-352. doi:10.1007/s00221-009-2039-3.

Francisco Varela, Evan Thompson, Eleanor Rosch. 1991. The Embodied Mind. Cognitive Science and Human Experience, MIT Press, Cambridge.

Received February 2018; revised August 2018; accepted August 2018.

Studies in Digital Heritage, Vol. 2, No. 1, Publication date: September 2018 